\title{
Rhombomere rotation reveals that multiple mechanisms contribute to the segmental pattern of hindbrain neural crest migration
}

\author{
John Sechrist, Talma Scherson and Marianne Bronner-Fraser* \\ Developmental Biology Center, University of California, Irvine, Ca. 92717, USA \\ ${ }^{*}$ Author for correspondence
}

\section{SUMMARY}

Hindbrain neural crest cells adjacent to rhombomeres 2 (r2), r4 and r6 migrate in a segmental pattern, toward the first, second and third branchial arches, respectively. Although all rhombomeres generate neural crest cells, those arising from $r 3$ and $r 5$ deviate rostrally and caudally (J. Sechrist, G. Serbedzija, T. Scherson, S. Fraser and M. Bronner-Fraser (1993) Development 118, 691-703). We have altered the rostrocaudal positions of the cranial neural tube, adjacent ectoderm/mesoderm or presumptive otic vesicle to examine tissue influences on this segmental migratory pattern. After neural tube rotation, labeled neural crest cells follow pathways generally appropriate for their new position after grafting. For example, when r3 and $r 4$ were transposed, labeled $r 3$ cells migrated laterally to the second branchial arch whereas labeled $r 4$ cells primarily deviated caudally toward the second arch, with some cells moving rostrally toward the first. In contrast to r4 neural crest cells, transposed $r 3$ cells leave the neural tube surface in a polarized manner, near the $r 3 / 4$ border. Surprisingly, some labeled neural crest cells moved directionally toward small ectopic otic vesicles that often formed in the ectoderm adjacent to grafted r4. Similarly, they moved toward grafted or displaced otic vesicles. In contrast, surgical manipulation of the mesoderm adjacent to $r 3$ and $r 4$ had no apparent effects. Our results offer evidence that neural crest cells migrate directionally toward the otic vesicle, either by selective attraction or pathway-derived cues.

Key words: rhombomere, neural crest, cell migration

\section{INTRODUCTION}

The hindbrain has become an important system for examination of pattern formation and positional information in the developing nervous system. In the chick embryo, the developing hindbrain is subdivided into eight segments called rhombomeres. Neurogenesis in the hindbrain is iterative, occurring first in the even-numbered rhombomeres, followed by oddnumbered ones (Lumdsen and Keynes, 1989). Rhombomeres represent "compartments" of lineage restriction; thus, clones of cells do not cross rhombomere boundaries (Fraser et al., 1990). In addition, even and odd rhombomeres have different adhesive properties, and form boundaries when they are juxtaposed (Guthrie and Lumsden, 1991; Graham et al., 1993). The rostral portion of rhombomere boundaries correspond to borders of gene expression for several regulatory transcription factors (Hunt et al., 1991), presumed to be determinants of rhombomere phenotype. Some of the same genes are expressed in the corresponding neural crest populations that emigrate from particular rhombomeres (Hunt et al., 1991). In addition, transplanted rhombomeres maintain expression of Hox genes indicative of their original position even after being grafted to an ectopic site (Guthrie et al., 1992; Kuratani and Eichele, 1993). Taken together, these studies suggest that rhombomeres contain intrinsic segmental information that is important for neuronal differentiation and patterning.

Shortly after its closure, neural crest cells emigrate from the dorsum of the neural tube, following pathways that are characteristic of their axial levels of origin. In the hindbrain, the pattern of neural crest migration is segmented into three broad streams emanating laterally adjacent to rhombomeres (r) r1/2, $\mathrm{r} 4$ and r6. The first stream populates the trigeminal ganglion, maxillary and mandibular arches; the second contributes to the hyoid arch, geniculate and vestibular ganglia; the third populates the third and fourth branchial arches, superior, petrosal and nodose ganglia (Noden, 1975; Anderson and Meier, 1981; D’Amico-Martel and Noden, 1983; Lumsden et al., 1991). This segmental migratory pattern could arise from inherent properties of the neural tube leading to a non-uniform generation of neural crest cells. This idea receives support from dye labelling experiments of Lumsden and colleagues (Lumsden et al., 1991; Graham et al., 1993), who propose that r3 and r5 fail to produce neural crest cell, perhaps due to cell death. However, focal injections of DiI have shown that all rhombomeres, including $\mathrm{r} 3$ and $\mathrm{r} 5$, can generate neural crest cells (Sechrist et al., 1993). Another possibility is that the segmental migratory pattern may be imposed by tissues through which neural crest cells migrate. This is clearly the 
case in the trunk region, where the selective pattern of neural crest cell migration through the rostral, but not caudal, sclerotome is imposed by the mesoderm (Keynes and Stern, 1984; Bronner-Fraser and Stern, 1991).

To characterize the mechanisms underlying cell migration in the hindbrain, we have challenged neural crest migratory pathways by performing a series of microsurgical experiments, including neural tube rotations, mesoderm rotations and otic placode grafts in combination with dye-labelling. These manipulations were designed to distinguish between the respective roles of the rhombomeres themselves and the surrounding tissues in generating the segmental pattern of hindbrain neural crest cell migration. Specifically, we asked: (1) if neural crest cells leave the neural tube at specific exit sites; (2) if neural crest cells are attracted toward their targets by positive cues along the pathway of migration or emanating from their targets; and/or (3) if there are inhibitory barriers to neural crest migration that may prevent cell migration through specific regions. We have found that rotation of the neural tube does not alter the segmental pattern of neural crest cell migration, as cells migrate in a manner generally appropriate to their new location. Interestingly, DiI-labeled neural crest cells moved directionally toward the otic vesicles, formed either by grafting rhombomere 4 into a new position or by grafting an additional otic placode adjacent to rhombomeres $2 / 3$. In contrast, rotation of the mesoderm had no obvious effect on the pattern of neural crest migration. The present study is the first to demonstrate that signals from another tissue, the otic vesicle, can influence the pattern of neural crest migration in the hindbrain.

\section{MATERIALS AND METHODS}

\section{Embryos}

White Leghorn chick embryos were incubated at $38^{\circ} \mathrm{C}$ until they reached the desired stages of development (7-13 somite stages; stages 9-11 of Hamburger and Hamilton, 1951). After a window was cut in the egg, Indian Ink (Pelikan Fount; diluted 1:10 in phosphate-buffered saline or Howard's Ringers solution) was injected under the blastoderm. The vitelline membrane was deflected from above the embryo using a sharpened tungsten needle.

\section{Focal injections of Dil}

An $0.5 \%$ stock solution (weight/volume) of 1,1-dioctadecyl-3,3,3',3'tetramethylindocarbocyanine perchlorate (DiI, Molecular Probes) was
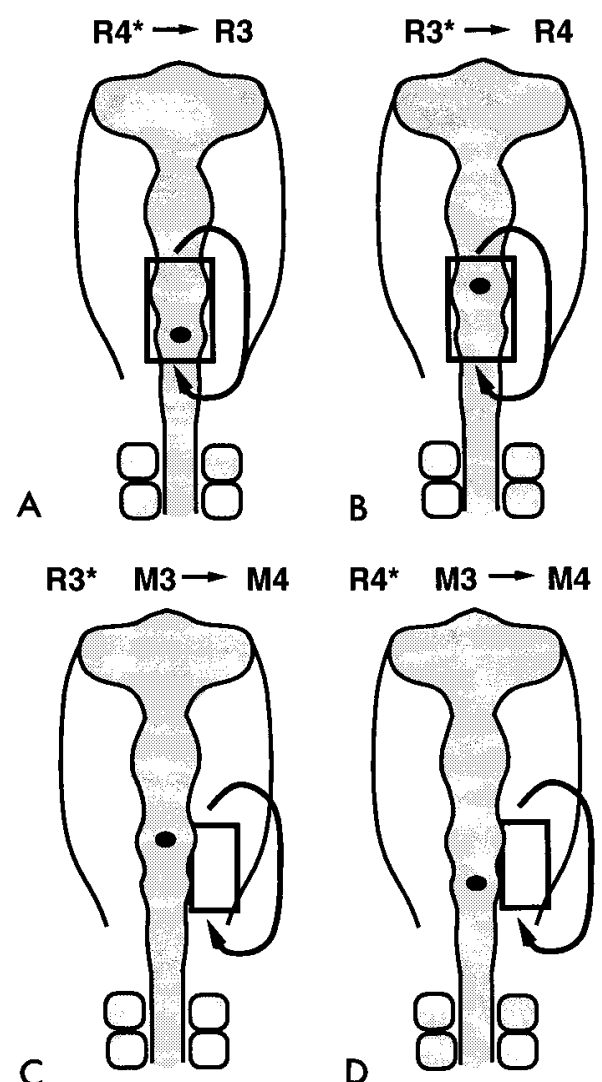

Fig. 1. Schematic diagrams illustrating neural tube and ectoderm/mesoderm rotations. (A, B) For neural tube rotations, the tissue was freed from adjacent tissue using a fine glass needle and rotated $180^{\circ}$ rostrocaudally. In most cases, the whole neural tube, plus the notochord, was rotated, transposing the positions of either $\mathrm{r} 3$ and r4 or r5 and r6. (C, D) For ectoderm/mesoderm rotations, a rectangular piece of tissue adjacent to $\mathrm{r} 3$ and $\mathrm{r} 4$ was cut as described above and rotated $180^{\circ}$ rostrocaudally. The pattern of neural crest migration was assessed by applying a small focal injection of the vital dye, DiI, into the indicated rhombomere ( $\mathrm{r} 3$ or $\mathrm{r} 4$ ) prior to rotation or using a neurofilament antibody. $\mathbf{r} 4 * \rightarrow \mathbf{r} 3=$ labeled $r 4$ cells rotated to the position of $r 3 ; \mathbf{r} 3 * \rightarrow \mathbf{r} 4=$ labeled $r 3$ cells rotated to the position of $\mathrm{r} 4 ; \mathbf{r} 3 * \mathbf{m} 3 \rightarrow \mathbf{m} \mathbf{4}=$ labeled $\mathrm{r} 3$ cells with mesoderm adjacent to $\mathrm{r} 3$ rotated to the position adjacent to $\mathrm{r} 4 ; \mathbf{r} \mathbf{4}^{*} \mathbf{m} \mathbf{3} \rightarrow \mathbf{m} \mathbf{4}=$ labeled $\mathrm{r} 4$ cells with mesoderm adjacent to $r 3$ rotated to the position adjacent to $r 4$.

Table 1. Summary of rhombomere and ectoderm/mesoderm rotations

\begin{tabular}{|c|c|c|c|c|c|c|}
\hline Operation & Label & $\begin{array}{l}\text { Stage of } \\
\text { operation }\end{array}$ & $\begin{array}{l}\text { Stage of } \\
\text { analysis }\end{array}$ & $\begin{array}{l}\text { No. } \\
\text { embryos }\end{array}$ & $\begin{array}{l}\text { Extra otic } \\
\text { vesicles }\end{array}$ & Migration pattern \\
\hline $\begin{array}{l}\text { Rotation r3/4 } \\
\quad \text { (rostrocaudal) }\end{array}$ & $\begin{array}{l}\text { NF-M } \\
\text { DiI in r3 } \\
\text { DiI in r4 }\end{array}$ & $\begin{array}{l}7-9 \text { ss } \\
8-12 \text { ss } \\
8-12 \text { ss }\end{array}$ & $\begin{array}{l}20-24 \text { ss } \\
16-21 \text { ss } \\
16-22 \text { ss }\end{array}$ & $\begin{array}{c}6 \\
35 \\
16\end{array}$ & $\begin{array}{c}4 \\
14+ \\
5\end{array}$ & $\begin{array}{l}\text { Cells deviate caudally toward otic } \\
\text { vesicle and arch } 2 \text { and toward } \\
\text { extra otic vesicle }\end{array}$ \\
\hline $\begin{array}{l}\text { Rotation } \mathrm{r} 3 / 4 \\
\quad \text { (rostrocaudal+ } \\
\text { dorsoventral) }\end{array}$ & $\begin{array}{l}\text { NF-M } \\
\text { DiI in r4 } \\
\text { DiI in r3 }\end{array}$ & $\begin{array}{l}11 \mathrm{ss} \\
10-13 \mathrm{ss} \\
9-11 \mathrm{ss}\end{array}$ & $\begin{array}{l}24 \text { ss } \\
20-27 \text { ss } \\
24-27 \text { ss }\end{array}$ & $\begin{array}{l}1 \\
5 \\
4\end{array}$ & $\begin{array}{l}1 \\
5 \\
4\end{array}$ & $\begin{array}{l}\text { Cells migrate ventrally above foregut, then } \\
\text { dorsally toward ectopic and endogenous } \\
\text { otic vesicles or } 2 \text { nd arch }\end{array}$ \\
\hline $\begin{array}{l}\text { Rotation r5/6 } \\
\quad \text { (rostrocaudal) }\end{array}$ & $\begin{array}{l}\text { DiI in r5 } \\
\text { DiI in r6 }\end{array}$ & $\begin{array}{l}11-13 \text { ss } \\
11-12 \text { ss }\end{array}$ & $\begin{array}{l}18-20 \mathrm{ss} \\
18-21 \mathrm{ss}\end{array}$ & $\begin{array}{l}8 \\
6\end{array}$ & $\begin{array}{l}0 \\
0\end{array}$ & $\begin{array}{l}\text { Cells to 3rd arch } \\
\text { Cells to 2nd and 3rd arch }\end{array}$ \\
\hline $\begin{array}{l}\text { Rotation r4-6 } \\
\quad \text { (rostrocaudal) }\end{array}$ & $\begin{array}{l}\text { DiI in } \mathrm{r} 4 \\
\text { DiI in r6 }\end{array}$ & $\begin{array}{l}8-10 \mathrm{ss} \\
8-10 \mathrm{ss}\end{array}$ & $\begin{array}{l}20-22 \mathrm{ss} \\
16-21 \mathrm{ss}\end{array}$ & $\begin{array}{l}4 \\
5\end{array}$ & $\begin{array}{l}0 \\
0\end{array}$ & $\begin{array}{l}\text { Cells to } 2 \text { nd and } 3 \mathrm{rd} \text { arch } \\
\text { Cells to } 2 \text { nd arch }\end{array}$ \\
\hline $\begin{array}{l}\text { Rotation ectoderm/ } \\
\text { mesoderm at r3/4 } \\
\text { level (rostrocaudal)1 }\end{array}$ & $\begin{array}{l}\text { NF-M } \\
\text { DiI in r3 } \\
\text { DiI in } r 4\end{array}$ & $\begin{array}{l}7 \mathrm{ss} \\
7-9 \mathrm{ss} \\
7-10 \mathrm{ss}\end{array}$ & $\begin{array}{l}22 \mathrm{ss} \\
16-20 \mathrm{ss} \\
17-22 \mathrm{ss}\end{array}$ & $\begin{array}{l}2 \\
4 \\
8\end{array}$ & $\begin{array}{l}- \\
2 \\
3\end{array}$ & $\begin{array}{l}\text { Cells migrate normally except } \\
\text { for a small stream to } \\
\text { extra otic vesicle }\end{array}$ \\
\hline
\end{tabular}


made in $100 \%$ ethanol. The injection micropipettes were back-filled with the DiI solution, attached to a forcedair pressure injection apparatus, which was inserted into the dorsal portion of neural tube just lateral to the midline using a micromanipulator (Narashige). A very small amount of the DiI solution was expelled, which was visible through the dissecting microscope as well as through the epifluorescence microscope as a small red spot of dye in the tissue. Rhombomere boundaries were used to guide the position of the micropipette and to judge the success of the injection. After injection, the eggs were sealed with cellophane tape and returned to the incubator until the indicated times of fixation. Only embryos in which the grafts healed well and were properly oriented were used in this study. Embryos in which the graft was poorly aligned or didn't heal properly were omitted from further analysis.

\section{Microsurgery}

Neural tube rotations, ectoderm/ mesoderm rotations, otic placode grafts and partial ablations were made using glass capillary tubes pulled on an electrode puller. For neural tube rotations, the tissue was freed from adjacent tissue using fine glass needles and rotated $180^{\circ}$ rostrocaudally (Fig. 1A,B). A lateral cut was made between the neural tube and adjacent mesenchyme as well as under the notochord. After separating the neural tube/notochord from adjacent tissue, they were cut transversely at the borders between selected rhombomeres.

In most cases, the whole neural tube, plus the notochord, was rotated rostrocaudally, while maintaining dorsoventral polarity. This resulted in transposition of the positions of either $\mathrm{r} 3$ and $\mathrm{r} 4, \mathrm{r} 5$ and $\mathrm{r} 6$ or $\mathrm{r} 4$ through r6. In a few cases, only the dorsal portion of the neural tube containing neural crest cells was rotated, either in place or to the opposite side in order to maintain mediolateral polarity of the graft. In some embryos, both the rostrocaudal and dorsoventral axes were inverted (see Table 1).

For ectoderm/mesoderm rotations, a rectangular piece of tissue adjacent to r3 and $\mathrm{r} 4$ was cut as described above for neural tube rotations, and rotated $180^{\circ}$ rostrocaudally (Fig. 1C,D). For otic vesicle ablations, the ectoderm lateral to $\mathrm{r} 4$ through $\mathrm{r} 6$ was removed by cutting a rectangular piece of ectoderm on one side of the embryo and removing it with fine forceps. For
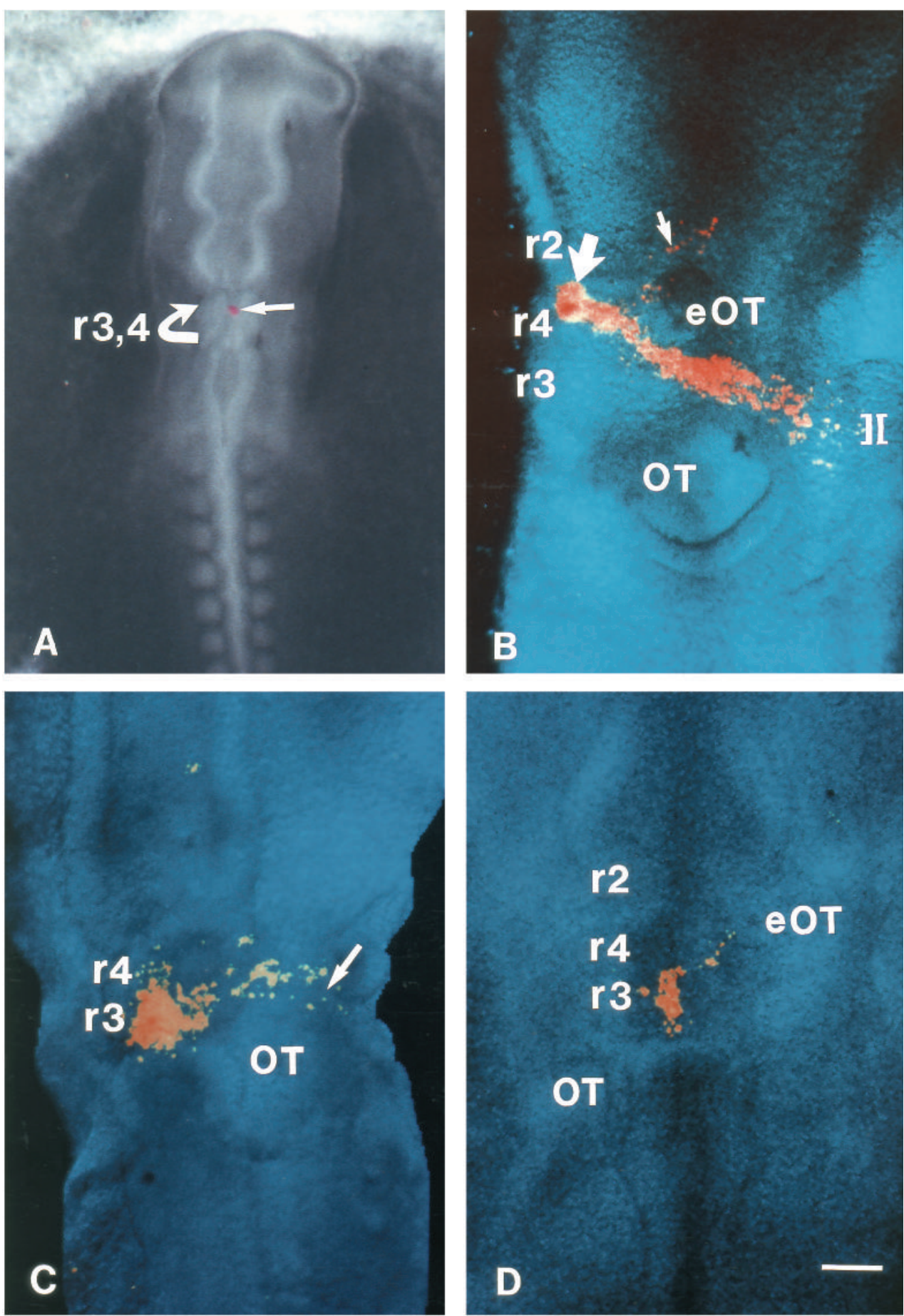

Fig. 2. Microsurgical rotations of $\mathrm{r} 3$ and $\mathrm{r} 4$ after DiI-labeling. (A) Photomicrograph of an 11-ss embryo viewed shortly after operation in which a focal injection of DiI (small arrow) was made into $\mathrm{r} 4$, followed by rotation of $\mathrm{r} 3$ and $\mathrm{r} 4(\mathbf{r} 4 * \rightarrow \mathbf{r} 3)$, as indicated by the curved arrow. (B) A confocal microscopic image of the same embryo after 16 hours, at the 20-ss. DiI-labeled cells have emerged from the injection site (large arrow) and have migrated caudally toward the endogenous otic vesicle (OT) and into the second branchial arch (II). A small ectopic otic vesicle (eOT) formed in this embryo at the r2/4 graft border, around which a small stream (small arrow) of DiI-labeled cells appeared to migrate toward the first branchial arch. (C) A confocal image of an $\mathbf{r} 3 * \rightarrow \mathbf{r} 4$ embryo that received a focal injection of DiI into $\mathrm{r} 3$ at the 9-ss and was fixed at the 17-ss. DiI-labeled cells coursed ventrolaterally from the injection site past the otic vesicle (OT) to invade the second branchial arch (arrow). (D) A confocal image of an $\mathbf{r}^{*} \rightarrow \mathbf{r} 4$ embryo that received a small focal injection of DiI into $\mathrm{r} 3$ at the 9-ss and was fixed at the 17-ss. A small stream of DiI-labeled cells moved laterally and rostrally toward a small ectopic otic vesicle (eOT) at the $\mathrm{r} 2 / 4$ border. Bar, $240 \mu \mathrm{m}$ for A; $80 \mu \mathrm{m}$ for B-D. 
otic placode grafts, a small, rectangular piece of ectoderm lateral to r4 through r6 was dissected from the left side of the embryo and was then placed into a slit or shallow depression, made by removing some of the endogenous ectoderm, at the $\mathrm{r} 2 / 3$ border on the right side of the same embryo. The pattern of neural crest migration was assessed either by looking at the distribution of DiI-labeled or neurofilamentimmunoreactive cells (see below). Similar results were obtained with both analyses, suggesting that the observations do not result from the method of labelling alone.

\section{Fixation}

DiI-labeled embryos were fixed from 3 to 24 hours in $4 \%$ paraformaldehyde, washed in $0.1 \mathrm{M}$ phosphate buffer (PB) for 1 hour. In order to process embryos for neurofilament immunoreactivity, they were fixed as above or in cold $70 \%$ ethanol or $100 \%$ methanol overnight at $4^{\circ} \mathrm{C}$ and washed in $0.1 \mathrm{M}$ phosphate-buffered saline (PBS; pH 7.4).

\section{Preparation for cryostat sectioning}

After washing, embryos were placed sequentially in 5\% and $15 \%$ sucrose in PBS for 4-24 hours at $4^{\circ} \mathrm{C}$. Embryos then were incubated in $15 \%$ sucrose and $7.5 \%$ gelatin (Sigma, 300 Bloom) for 4 hours at $37^{\circ} \mathrm{C}$, followed by embedding in fresh gelatin. They were either cut immediately or stored at $4^{\circ} \mathrm{C}$ for up to one week. Embryos were quick-frozen in liquid nitrogen immediately before sectioning and allowed to equilibrate to $-25^{\circ} \mathrm{C}$ prior to cutting transverse $10 \mu \mathrm{m}$ sections on a Zeiss Microm cryostat. Sections of DiI-labeled embryos were mounted on subbed slides and viewed without a coverslip shortly after they were cut. Some DiI-labeled and unlabeled embryos were processed for immunohistochemistry as described below; embryos were stored at $-20^{\circ} \mathrm{C}$ until the time of staining.

\section{Immunohistochemistry}

A monoclonal antibody against the non-phosphorylated form of the intermediate molecular mass neurofilament protein (NF-M) was provided by Dr Virginia Lee (RMO 270.3; Lee et al., 1987). Sections were warmed to $25^{\circ} \mathrm{C}$. Approximately $20 \mu \mathrm{l}$ of antibody solution, diluted 1:300 in PBS containing 0.1\% BSA, was applied to each section and incubated overnight in a humidified chamber either at $4^{\circ} \mathrm{C}$ or $25^{\circ} \mathrm{C}$. Sections were washed in PBS for 5 minutes and incubated for 1 hour with highly fluorescent FITC-conjugated antibodies against mouse IgGs (Antibodies, Inc.) and coverslipped with gelmount (Biomeda).

\section{Microscopy}

Whole-mounted DiI-labeled embryos were viewed using a laser scanning confocal microscope (Biorad MRC 600 on a Zeiss Axiovert microscope). Slides with whole-mounted or sectioned embryos were also viewed with an Olympus Vanox or a Zeiss Axiophot Epifluorescence Microscope. A rhodamine filter set was used to visualize the DiI-labeled cells, while a fluorescein filter set was used to visualize neurofilament immunoreactivity. Data from the confocal microscope were stored on removable Bernoulli discs and images were processed using Adobe Photoshop software (Adobe Systems, Inc.) on a Macintosh IICi computer. Data from the conventional epifluorescence microscope were recorded photographically or using a Hamamatsu SIT camera and image processing was accomplished using the Vidim software system (Fraser, Stolberg and Belford, unpublished).

\section{RESULTS}

We have used a variety of grafting paradigms to determine whether the segmental pattern of neural crest migration in the hindbrain is established by signals within the neural tube, prior to emigration, or if patterns of migration are dependent on interactions within the migratory environment. To test the relative contributions of the neural tube and the external milieu, we performed rostrocaudal rotations of either the cranial neural tube or adjacent ectoderm/mesoderm as well as grafts of the otic placode. Tissue grafts were done between the 7 and 13 somite stage (ss), corresponding to stages of active neural crest cell emigration at this axial level (Lumsden et al., 1991; Sechrist et al., 1993). Except where noted, there was no correlation between the timing of the operation within this range of stages and the migratory patterns observed. Examples of the rotation operations are described schematically in Fig. 1; the numbers of embryos and results of neural tube and ectoderm/mesoderm rotations are summarized in Table 1.

Immediately after rotation of tissue through $180^{\circ}$ rostrocaudally (Fig. 2A), neural tubes and surrounding tissues appeared to be separated by a small gap, which healed rapidly, becoming integrated by approx. 3 hours after the operation. At the time of fixation, the graft borders were detectable in most embryos either due to the presence of a boundary or a slight mismatch in the neural tube widths at the graft/host interface. In most embryos, the pattern of neural crest migration was analyzed 12-24 hours following the operation by applying a small focal injection of the vital dye, DiI, into the indicated rhombomere (r3-r6) prior to the operation. In some cases, embryos were stained with a neurofilament (NF-M) antibody which recognizes migrating hindbrain neural crest cells (Sechrist et al., 1993).

Both neural tube and ectoderm/mesoderm rotation led to the juxtaposition of different rhombomeres and new regions of ectoderm. This resulted in the formation of small ectopic otic vesicles (Table 1). These formed adjacent to rotated $\mathrm{r} 4$ (Fig. 2B) after transposition of $\mathrm{r} 3$ and $\mathrm{r} 4 \quad(n=23 / 39$ embryos examined in detail for the presence of this structure) and adjacent to $\mathrm{r} 3$ after ectoderm/mesoderm rotations $(n=5 / 12$ embryos). The vesicles consisted of invaginated, thickened epithelium and were less than half the diameter of the endogenous otic vesicles but were otherwise morphologically indistinguishable. Others have noted accessory otic vesicles after grafting r4 to ectopic sites (Kuratani and Eichele, 1993), and their formation is not surprising given that the hindbrain is thought to induce the otic vesicle (Harrison, 1936).

\section{Caudorostral rotation of labeled $\mathrm{r} 4$ to the position of r3}

When labeled $\mathrm{r} 4$ cells were rotated to the position of $\mathrm{r} 3$ $\left(\mathbf{r} 4^{*} \rightarrow \mathbf{r} 3\right.$; Figs $\left.1 \mathrm{~A}, 2 \mathrm{~A}\right)$, their migratory trajectory was similar, but not identical, to that of endogenous $\mathrm{r} 3$ cells. Numerous DiIlabeled cells emerged after $\mathbf{r} 4 * \rightarrow \mathbf{r 3}$ ( $n=16$ embryos) and demonstrated similar migratory patterns in all embryos. The majority of cells coursed caudally as a broad stream toward the endogenous otic vesicle, around which they migrated into the second branchial arch (Figs 2B, 3A,B). This pattern resembled that of labeled $\mathrm{r} 3$ cells in unoperated embryos, as illustrated in Fig. 3G, with two consistent differences. First, r4* $\rightarrow$ r3 typically produced more neural crest cells than normal $\mathrm{r} 3$ cells. Second, $\mathbf{r} 4 * \rightarrow \mathbf{r} 3$ cells entered the mesenchyme adjacent to $\mathrm{r} 3$ whereas normal $\mathrm{r} 3$ neural crest cells did not invade this mesoderm. The presence of DiI-labeled neural crest cells in this region is apparent by examining either transverse (Fig. 3A) or longitudinal (Fig. 3B) sections through embryos 1 day after neural tube rotation. 

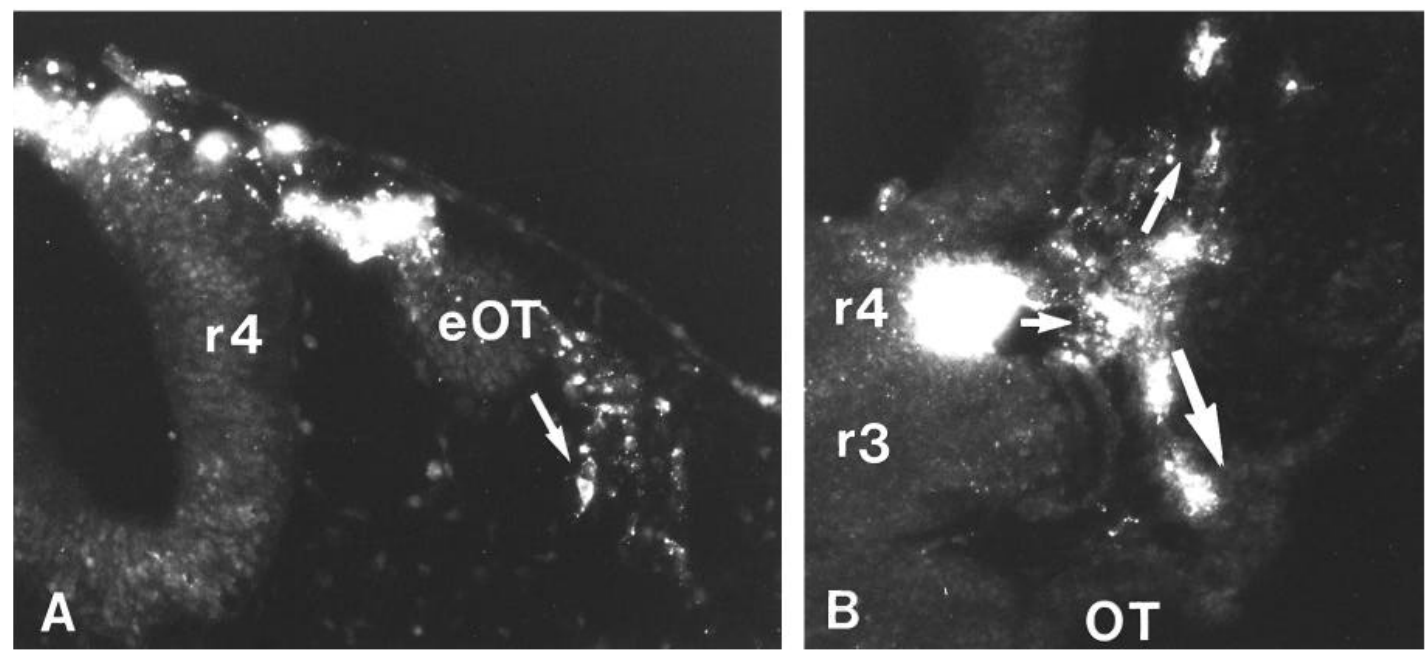

Fig. 3. Epifluorescence photomicrographs of sections through embryos after rostrocaudal rotation of the neural tube at the levels of $r 3$ and $r 4$. (A) A transverse section through an embryo in which $\mathrm{r} 4$ was labeled at the 10-ss, prior to caudorostral rotation of $\mathrm{r} 3$ and $\mathrm{r} 4(\mathbf{r} 4 * \rightarrow \mathbf{r} 3)$. By the $23-$ ss, DiI-labeled neural crest cells have migrated laterally into the mesenchyme toward an ectopic otic vesicle (eOT).

Some then moved ventrocaudally (arrow) beyond the otic vesicle toward the first epibranchial
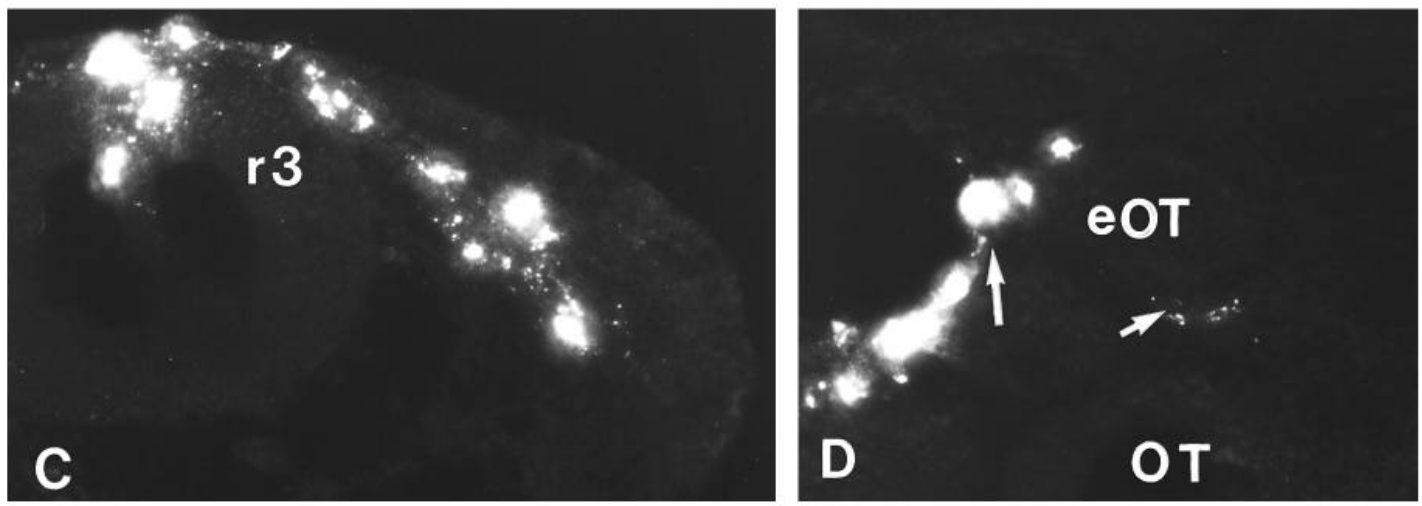

placode and second

branchial arch. (B) A

longitudinal section through an embryo labeled at the 10ss and fixed at the 20-ss after $\mathbf{r} 4^{*} \rightarrow \mathbf{r} 3$ rotation. Labeled cells (arrow) entered the mesenchyme that would be adjacent to $\mathrm{r} 3$ and migrated caudally toward the endogenous otic vesicle (downward arrow) or rostrally toward the first branchial arch (upward arrow). (C) Transverse

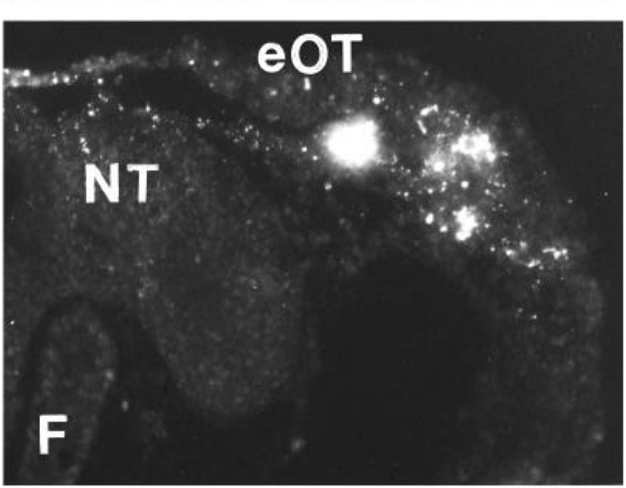

E

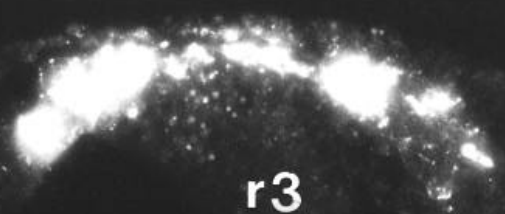

section through the embryo illustrated in whole-mount in Fig. 2C which underwent $\mathbf{r} 3^{*} \rightarrow \mathbf{r} 4$ rotation at the 9 -ss and fixation at the 17-ss. DiIlabeled cells migrated

laterally toward the second branchial arch.

(D) Longitudinal section through the embryo shown in whole-mount in Fig. 2D after $\mathbf{r} 3^{*} \rightarrow \mathbf{r} 4$ rotation at the 9-ss and fixation at the 17-ss. A single file of labeled cells (arrow) migrated rostrally toward and surrounded a small ectopic otic vesicle (small arrow; eOT).

(E,F) Transverse sections through an embryo after $\mathbf{r} 3 * \rightarrow \mathbf{r} 4$ rotation at the 10 -ss and fixation at the 16-ss. In E, many DiI-labeled cells migrated laterally and rostrally across the midline.

Further rostrally, in F, some DiI-labeled cells moved toward an ectopic otic

vesicle (eOT) at the $\mathrm{r} 2 / 4$ border of the rotated neural tube (NT). (G) An embryo in which $\mathrm{r} 3$ was labeled with DiI at the 9-ss and fixed at the 15-ss.

Labeled cells preferentially emerged near the $\mathrm{r} 3 / 4$ border (arrow). (H) An embryo in which $\mathrm{r} 3$ was labeled prior to rostrocaudal $\mathbf{r} 3^{*} \rightarrow \mathbf{r} 4$ rotation at the 8 ss and fixation at the 21-ss. Labeled cells from $\mathrm{r} 3$ appeared to leave the neural tube primarily at a dorsal "exit point" (arrow) close to the r3/4 border and then migrated into the second (II) branchial arch. Bar, $40 \mu \mathrm{m}$ in A-F and $75 \mu \mathrm{m}$ in G, H. 

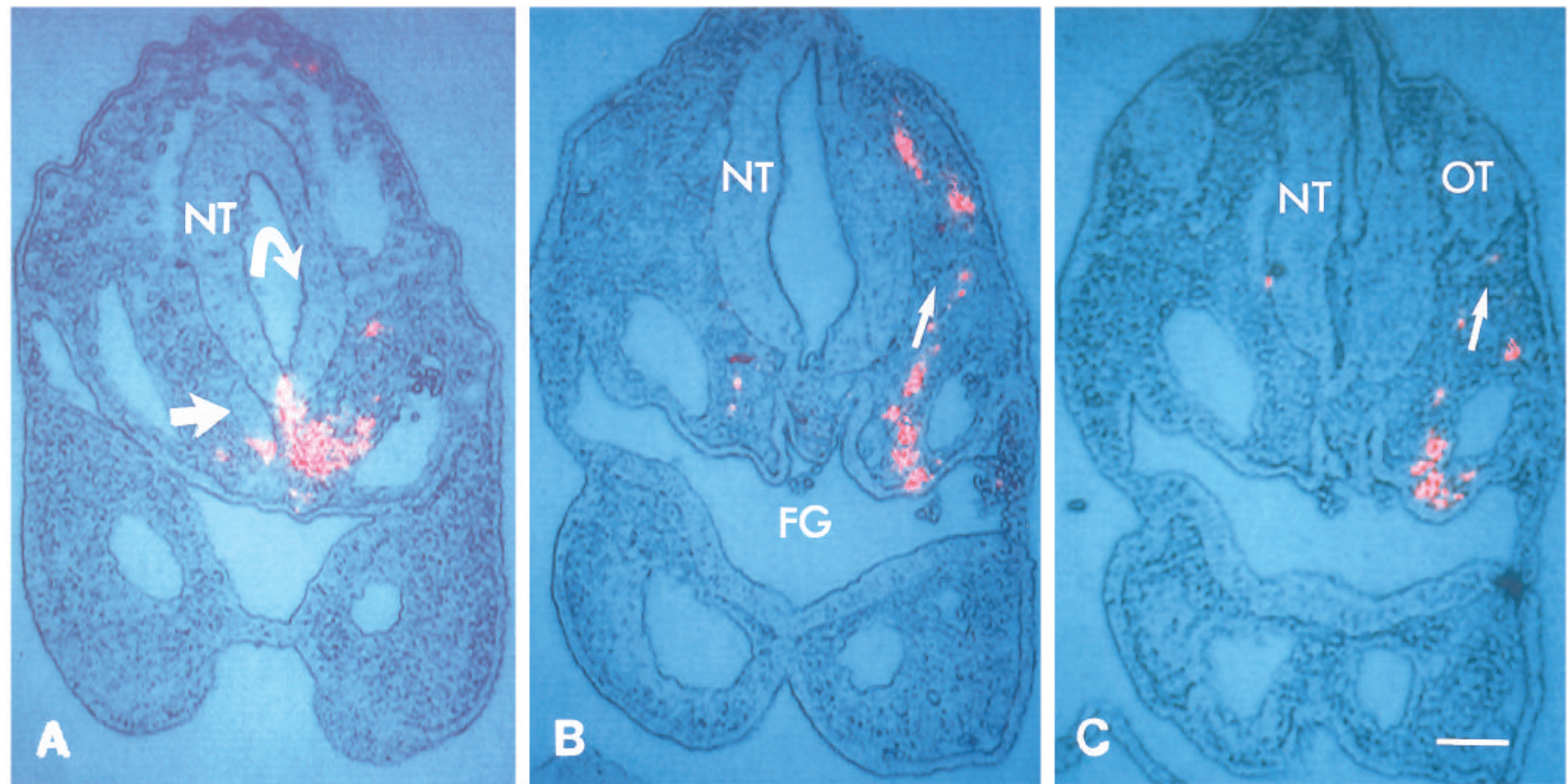

Fig. 4. Rostrocaudal and dorsoventral neural tube rotation. (A-C) Three rostral to caudal transverse sections through an embryo in which the neural tube was rotated rostrocaudally at $\mathrm{r} 3$ and $\mathrm{r} 4$ and then dorsoventrally (curved arrow), such that the ventral portion of the neural tube (NT) was located dorsally. DiI-labeled r4 neural crest cells emerged ventrally just above the foregut (FG) and migrated toward a small ectopic vesicular structure (broad arrow) dorsal to the foregut; other neural crest cells entered the 1st or 2 nd branchial arch, or migrated dorsally (upward arrow) toward the endogenous otic vesicle (OT). Bar, $80 \mu \mathrm{m}$.
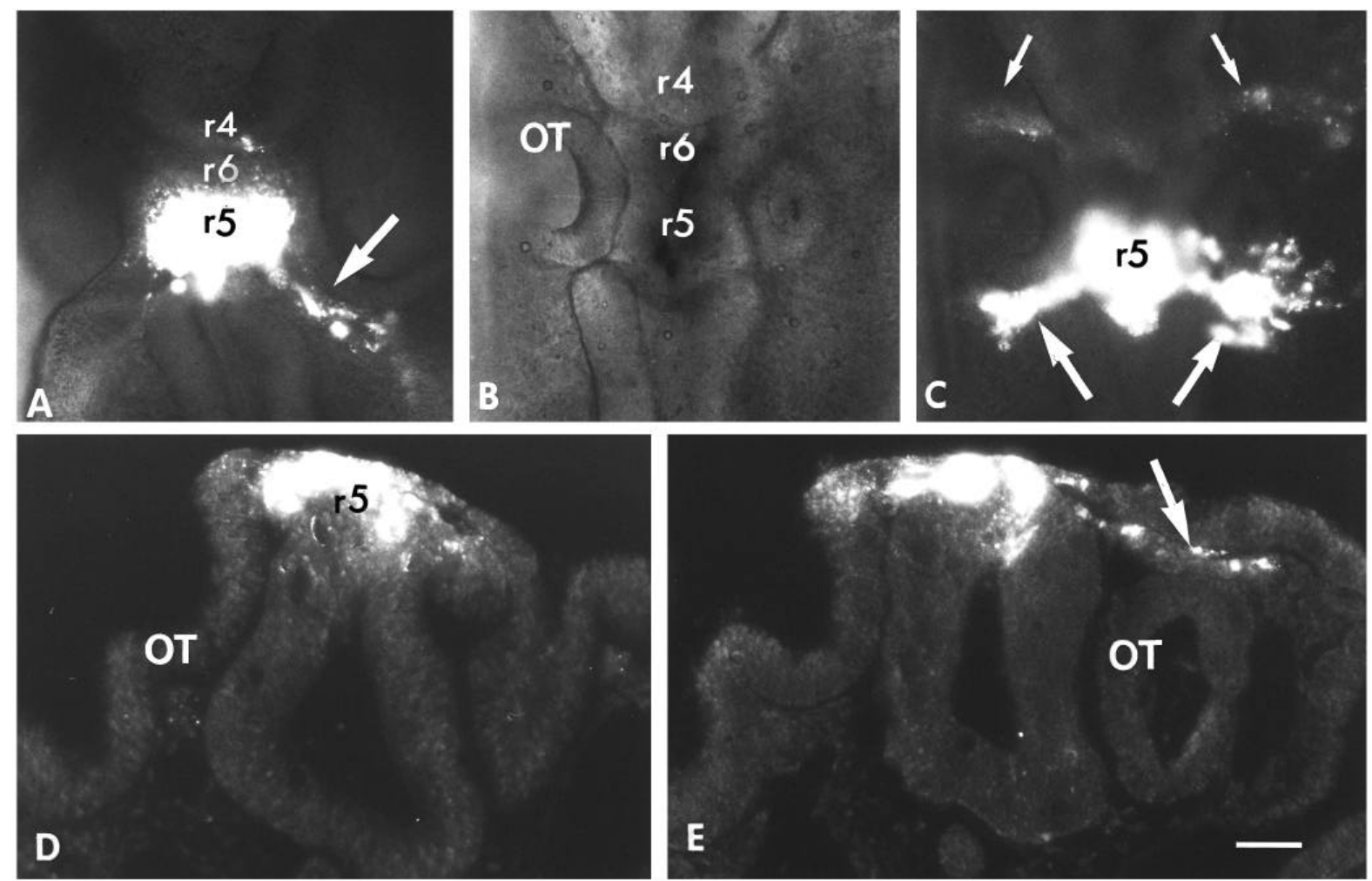

Fig. 5. Microsurgical rotations of rhombomeres 5 and 6 after DiI-labeling. (A) An epifluorescence image of an $\mathbf{r}^{*} \rightarrow \mathbf{r 6}$ embryo that received a focal injection of DiI into $\mathrm{r} 5$ at the 13 -ss and was fixed at the 19-ss. Numerous labeled cells (arrow) moved laterally and caudally toward the $3 \mathrm{rd}$ branchial arch. (B,C) A phase (B), and epifluorescence image (C) of an $\mathbf{r} 5^{*} \rightarrow \mathbf{r 6}$ embryo that received a focal injection of DiI into r5 at the 13 -ss and was fixed at the 19-ss. In this embryo, DiI label was injected into 55 prior to $\mathbf{r 5}^{*} \rightarrow \mathbf{r 6}$ rotation, but a small portion of labeled $\mathbf{r} \mathbf{5}^{*}$ was left in its original orientation while the rest of the rhombomere was rotated. A few labeled cells (small arrows) from unrotated $\mathrm{r} 5 \mathrm{can}$ be seen moving rostrally toward the second branchial arch. In addition, numerous labeled cells (large arrows) from rotated $\mathbf{r} 5 *$ moved laterally and caudally toward the third branchial arch. Note that the otic vesicle on the right was invaginated more than that seen in normal embryos (see sections below). (D,E) Transverse epifluorescence sections through the same embryo as in B and C showing that labeled neural crest cells from $\mathbf{r 5}^{*}$ are trapped between the neural tube and intact paired otic vesicle on the left, but migrate dorsal (arrow) to the invaginated, smaller otic vesicle on the right side. Bar, $80 \mu \mathrm{m}$ in A-C; $40 \mu \mathrm{m}$ in D-E. 
When rotation of the neural tube led to the differentiation of a small ectopic otic vesicle (Fig. 2B) at the border between $\mathrm{r} 2$ and rotated $\mathrm{r} 4$, some DiI-labeled cells migrated toward this otic vesicle, as a small rostrally directed branch which joined neural crest cells emanating from $\mathrm{r} 2$ (Fig. 2B, small arrow). After reaching the accessory otic vesicle, some labeled cells continued toward the first branchial arch where they were observed adjacent to the dorsolateral (trigeminal) placode.

\section{Rostrocaudal rotation of labeled $r 3$ to the position of r4}

When the neural tube was rotated rostrocaudally and the label was contained in $\mathrm{r} 3\left(\mathbf{r}^{*} \rightarrow \mathbf{r} 4\right.$; Fig. 1B), many DiI-labeled neural crest cells emerged and migrated away from the site of injection ( $n=35$ embryos; Table 1 ), supporting the conclusion that $r 3$ generates neural crest cells (Sechrist et al., 1993). The DiI-labeled cells migrated laterally into the second branchial arch (Figs 2C, 3C) in all embryos that lacked an ectopic otic vesicle (see below). The pathways of migration in $\mathbf{r} 3 * \rightarrow \mathbf{r} \mathbf{4}$ embryos correspond to those normally followed by cells emerging from r4. However, careful analysis of serial sections through these embryos reveals that the pattern of emigration of $\mathbf{r} 3 * \rightarrow \mathbf{r} 4$ embryos is not identical to that observed for neural crest cells emigrating from unoperated r4. Cells emerging from r4 normally migrate directly into the lateral mesenchyme. In contrast, neural crest cells originating from $\mathbf{r} 3^{*} \rightarrow \mathbf{r} 4$ appeared to move to a portion of the neural tube close the r3/4 border, perhaps representing a discrete exit point (Figs 2D, 3H) identical to that seen in unoperated embryos (Fig. 3G), where neural crest cells shift caudally toward the r3/4 border.

In approximately half of the embryos in which an accessory otic vesicle formed, DiI-labeled cells from $\mathbf{r} 3 * \rightarrow \mathbf{r} 4$ migrated rostrally toward it (Figs 2D, 3D$\mathrm{F})$ in addition to coursing as a caudal stream toward the endogenous otic vesicle on the same or opposite side of the embryo. Fig. 2D shows an embryo in which a small stream of DiI-labeled cells migrated toward the ectopic, but not the endogenous, otic vesicle. A single-file of cells emerged from a small focal injection into r3* after rotation to the r4 position. These cells moved directionally toward the rostral portion of the small otic vesicle at the r2/4 interface. In longitudinal section (Fig. 3D), DiI-labeled cells are visible surrounding the ectopic otic vesicle.
In two cases, only the dorsal portion of the neural tube containing neural crest cells was rotated rostrocaudally, either in place or to the opposite side in order to maintain mediolateral polarity of the graft. This operation resulted in transposing the position of the $\mathrm{r} 3$ and $\mathrm{r} 4$ neural crest without altering the ventral portion of the neural tube. The pattern of neural crest migration after neural fold rotation was similar to that observed with whole neural tube rotations (data not shown).

Labeled neural crest cells emerged from rotated $r 3$ for a limited time. Grafts performed at $\geq 12$-ss ( $n=2$ embryos a 13-ss) rarely produced labeled neural crest cells. This may be due to selective cell death in $\mathrm{r} 3$ around this time (Lumsden et al., 1991; Jeffs et al., 1992; Graham et al., 1993). For this reason, grafts including labeled $\mathrm{r} 3$ were performed at the 11-ss or younger.

\section{Rostrocaudal and dorsoventral rotation of r3 and r4}

In 10 embryos, both the rostrocaudal and dorsoventral orientations of the neural tube were inverted $180^{\circ}$ for $\mathbf{r} 3 * \rightarrow \mathbf{r} 4$ and $\mathbf{r} \mathbf{4}^{*} \rightarrow \mathbf{r} 3$ rotations (Table 1 ). In all of these embryos, small vesicular structures arose dorsal to the foregut, and lateral to
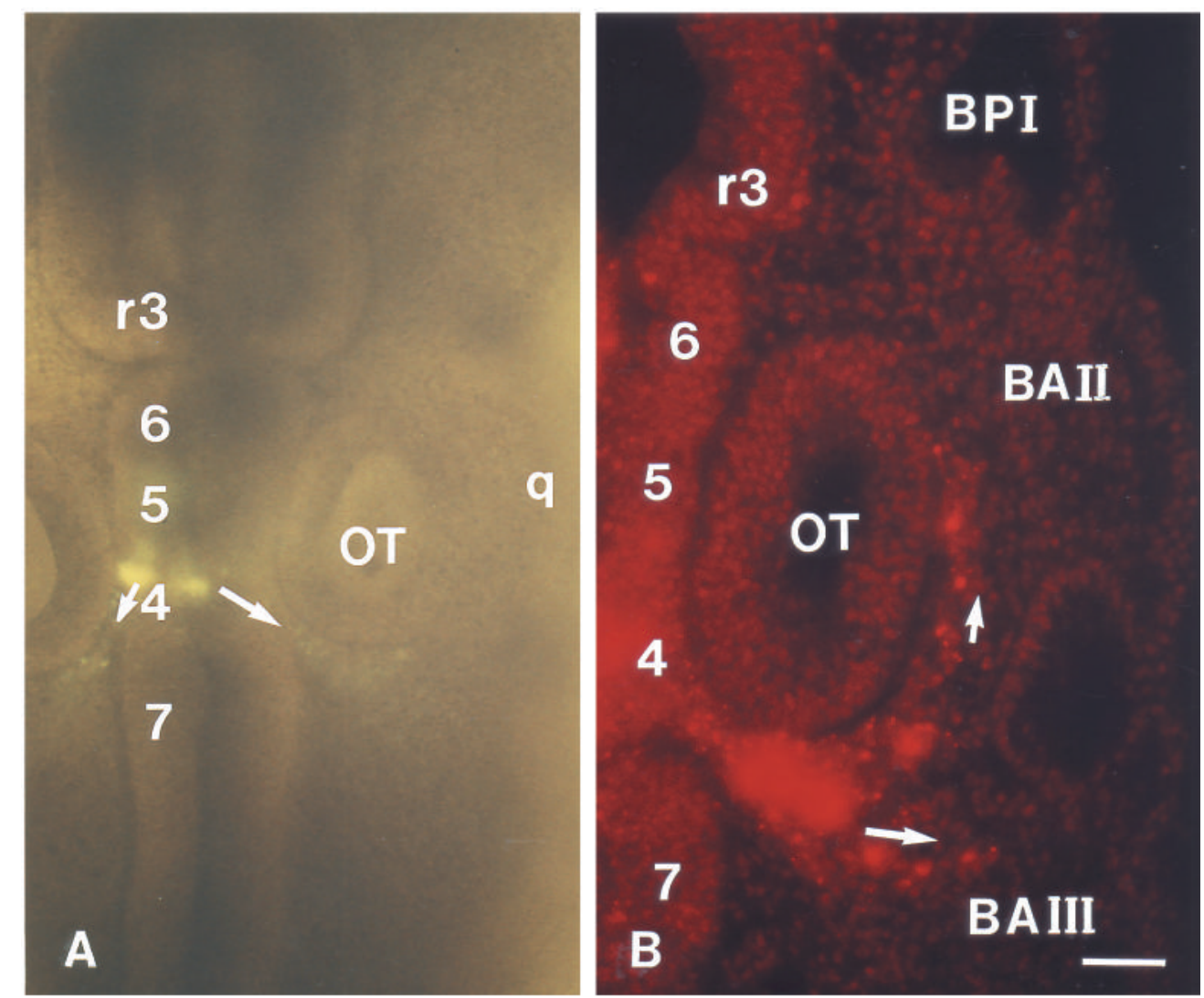

Fig. 6. Microsurgical rotations of rhombomeres 4, 5 and 6 after DiI labeling. (A) An epifluorescence image superimposed with phase image, viewed through the fluorescein filter set, of an embryo that received a focal injection of DiI into $\mathrm{r} 4$ at the 10 -ss and was fixed at the 20 -ss. The DiI-labeled cells (yellow) can be seen in rotated $\mathrm{r} 4$ and in neural crest cells (arrows) migrating caudal to the otic vesicles (OT). (B) An epifluorescence image of an oblique longitudinal section through the ventral otic vesicle of the same embryo, viewed through the rhodamine filter set. The smaller migratory stream of DiI-labeled r 4 cells migrated caudal to the otic vesicle toward the third branchial arch (longer arrow), as cells would normally if emerging from unoperated r6. However, in this embryo, some labeled cells proceeded rostrally (short arrow) toward the ventral and rostral portion of the otic vesicle, which is the normal target for cells from un-rotated $\mathrm{r} 4$. The rhombomeres, first branchial pouch (BPI), second (BAII) and third branchial (BAIII) arches are labeled for orientation. Bar, $80 \mu \mathrm{m}$ in A; $40 \mu \mathrm{m}$ in B. 
the midline (Fig. 4A, arrow). These probably formed from rotated dorsal ectoderm but, in several cases they appeared to either form from or fuse with evaginated foregut endoderm (Fig. 4B). Neural crest cells emerged ventrally just above the foregut (Fig. 4A). They were observed only around the ectopic vesicles in $2 / 10$ cases. In other cases, they migrated dorsally and were found in proximity to the endogenous otic vesicle $(n=5 / 10$; Fig. $4 \mathrm{~B}, \mathrm{C})$ or entered the branchial arches $(n=3 / 10)$. Labeled cells were observed primarily in the second arch, though one embryo had label in both the first and second arches. These results demonstrate that neural crest cells can move both ventrally and dorsally along their migratory pathways. Both labeled r3 and r4 generated migrating neural crest cells after dorsoventral inversion, though more appeared to originate from labeled $\mathrm{r} 4$.

\section{Rostrocaudal rotation of $\mathrm{r} 5$ and $\mathbf{r 6}$}

In 14 embryos, the rostrocaudal position of $\mathrm{r} 5$ and $\mathrm{r} 6$ were exchanged. After this operation, labeled and rotated $\mathbf{r 5}^{*}$ cells behaved similarly to endogenous r6 cells and vice versa (Table 1). Labeled $\quad \mathbf{r 5}^{*} \rightarrow \mathbf{r 6}$ migrated caudally and laterally, below the endogenous otic vesicle (Fig. 5A-C). This pattern is indistinguishable from that of unoperated r6 cells. In contrast, r6 $*$ r5 migrated rostrally and caudally around the otic vesicle (data not shown), following a similar pattern to that of unoperated r5 cells. Interestingly, fewer neural crest cells appeared to arise from $\mathbf{r 6} \mathbf{6}^{*} \rightarrow \mathbf{r 5}$ than either unoperated $\mathbf{r 5}^{*}$ or $\mathbf{r} 5^{*} \rightarrow \mathbf{r 6}$ embryos. After transposition of r5 and r6, we did not detect ectopic the otic vesicles that were separate from the endogenous vesicle. However, by one day post-operation, otic vesicle was abnormally enlarged, with duplicated invaginations (Fig. 5D). Part of the vesicle was situated deeper under the ectoderm than in in $\mathrm{C} ; 30 \mu \mathrm{m}$ in $\mathrm{E}$. unoperated embryos (Fig. 5E), in which case migrating neural crest cells moved laterally between the otic vesicle and ectoderm. This contrasts with the pattern in unoperated
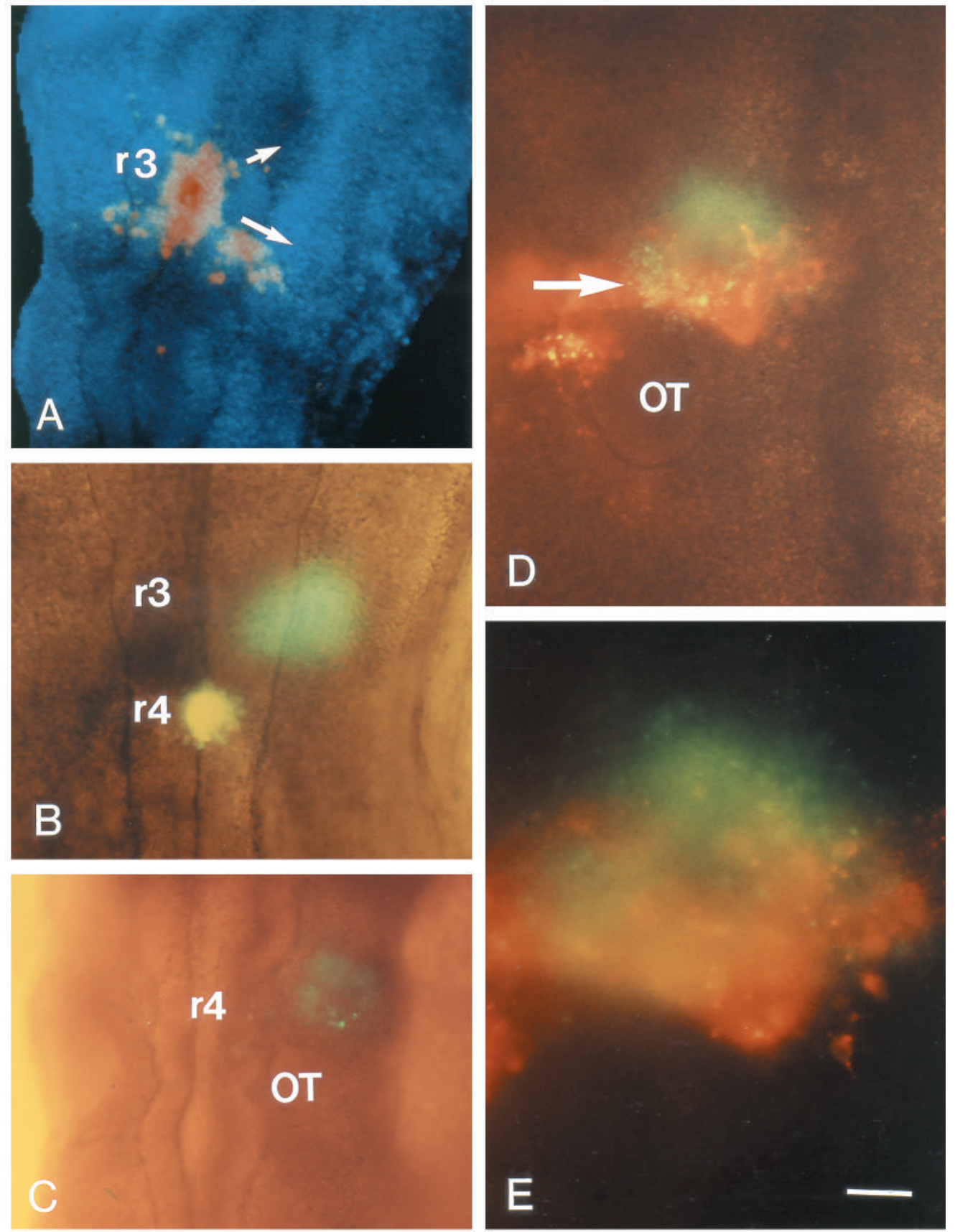

Fig. 7. Influences of ectoderm/mesoderm rotation on hindbrain neural crest migration. (A) A confocal image of an embryo labeled with DiI at $\mathbf{r} 3 *$ followed by rotation of the ectoderm/mesoderm $(\mathbf{m} 3 \rightarrow \mathbf{m} \mathbf{4})$ at the 8-ss and fixation at the 16-ss. The pattern of neural crest migration was unaltered by mesoderm rotation, with labeled cells (arrows) deviating rostrally and caudally to join the $\mathrm{r} 2$ and $\mathrm{r} 4$ streams. (B) A 9-ss embryo that was labeled with DiI (yellow) at $\mathrm{r} 4$ and $\mathrm{DiO}$ (green) in the mesoderm lateral to $\mathrm{r} 3$. (C) An embryo similar to the one shown in B that was labeled at the 8 -ss, rotated $\mathbf{m} 3 \rightarrow \mathbf{m} \mathbf{4}$ and fixed at the 19-ss; when viewed in whole-mount with phase imaging superimposed with fluorescence imaging viewed through the fluorescein filter set, the rotated $\mathbf{m} \mathbf{3}$ (green) is now lateral to $\mathrm{r} 4$ and rostral to the otic vesicle (OT). (D,E) The same embryo as that shown in B viewed laterally at the 20-ss. Double exposure through the fluorescein and rhodamine filter sets illustrates that "red" neural crest cells migrating laterally (arrow) beyond the otic vesicle (OT) toward the second branchial arch intermingle extensively with "green" mesodermal cells originating from rotated $\mathbf{m 3}$. Bar, $80 \mu \mathrm{m}$ in A,B,D; $90 \mu \mathrm{m}$ 

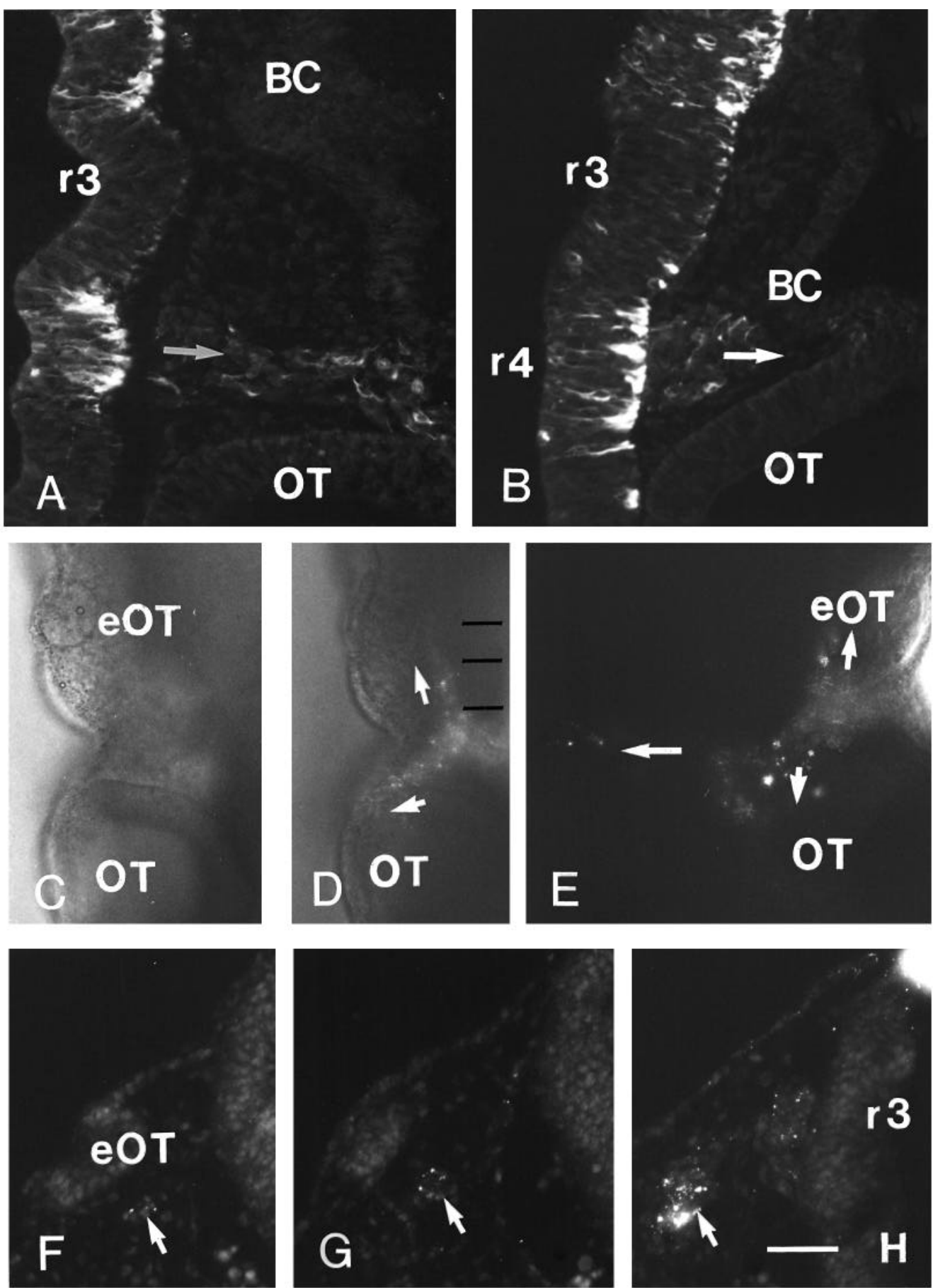

Fig. 8. Influences of ectoderm/mesoderm rotation on hindbrain neural crest migration. (A) A longitudinal section illustrating neurofilament immunoreactivity in an unoperated embryo. Neural crest cells emerged laterally from dorsal $r 4$ and migrated (arrow) rostral to the otic vesicle (OT) toward the 2nd branchial arch; the 1st branchial cleft (BC) formed lateral to the $\mathrm{r} 2 / 3$ border. (B) A longitudinal section through an embryo in which the ectoderm/mesoderm was rotated $(\mathbf{m} 3 \rightarrow \mathbf{m} \mathbf{4})$ adjacent to $\mathrm{r}$ and $\mathrm{r} 4$. After rotation of the ectoderm/mesoderm, the branchial cleft (BC) was repositioned just rostral to the otic vesicle. However, the pattern of neural crest migration (arrow) was identical to that shown in A. (C-E) Whole-mount images of an embryo labeled with DiI in $\mathrm{r} 3$ followed by an ectoderm/mesoderm $(\mathbf{m} 3 \rightarrow \mathbf{m} 4)$ rotation at the 9 -ss. Analysis was performed at the 21 -ss. A small ectopic otic vesicle (eOT) formed lateral to the $\mathrm{r} 2 / 3$ border, as observed in the whole-mount image (C). In a combined phase plus fluorescence image of the same embryo (D), DiI-labeled cells emerged from $\mathrm{r} 3$ and migrated caudally (arrow) toward the endogenous otic vesicle (OT). In addition, a small stream of cells moved rostrally (arrow) toward the ectopic otic vesicle. The black lines indicate the planes of section, from rostral to caudal, in F-H, respectively. (E) The movement of these cell can be observed particularly well in a side view of the embryo, which also shows a few neural crest cells (long arrow) near the 1st epibranchial placode region. (F-H) Transverse sections at the levels indicated in (D) showing a small stream of DiI-labeled cells moving toward an ectopic otic vesicle (eOT), contained in the rostral-most section (F). Arrows indicate the small stream of DiI-labeled cells. Note that the stream progressively thickens in more caudal sections (G-H). Bar, $40 \mu \mathrm{m}$ in A,B; $80 \mu \mathrm{m}$ in C-E; and $50 \mu \mathrm{m}$ in F-H. 
embryos in which neural crest cells become trapped between the otic vesicle, neural tube and ectoderm (Fig. 5D), consistent with the possibility that separating the ectoderm from the otic vesicle removes a mechanical inhibition.

\section{Rostrocaudal rotation of $\mathrm{r} 4, \mathrm{r} 5$ and $\mathrm{r} 6$}

By performing transpositions of two rhombomeres, we have produced confrontations between even/even and odd/odd rhombomeres. Because there appear to be miscibility differences between even and odd rhombomeres (Guthrie and Lumsden, 1991), it is possible that altering the even/odd confrontation may itself affect the pattern of neural crest migration. To control for this possibility, we performed larger rotations encompassing $\mathrm{r} 4$ through 6 in which either $\mathrm{r} 4$ or r6
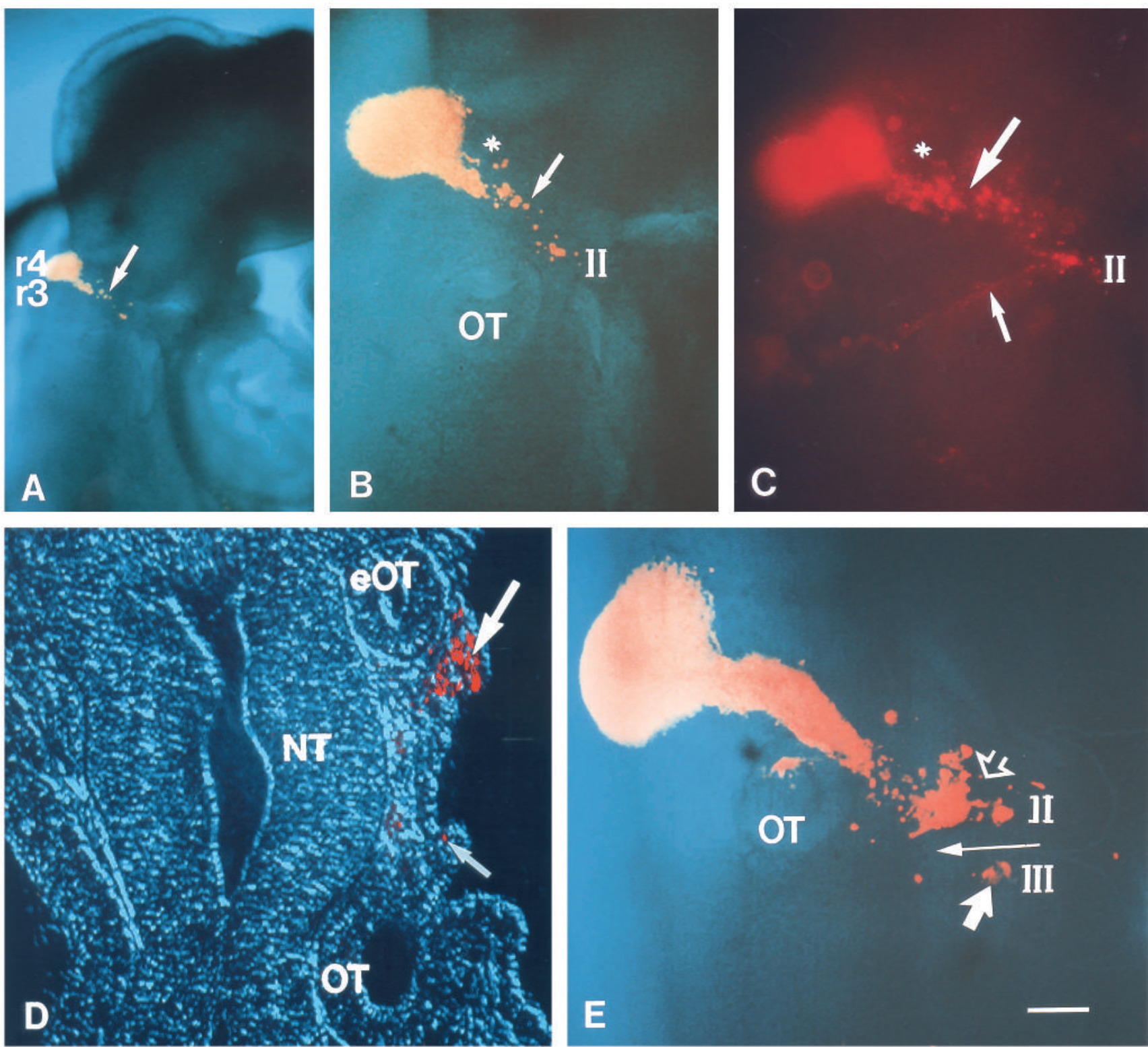

Fig. 9. Partial otic vesicle ablation with (A-D) or without (E) neural tube rotation. (A,B) Whole-mount phase image superimposed with epifluorescence image at low and high magnification of an embryo in which DiI label was injected into 4 prior to $\mathbf{r} 4 * \rightarrow \mathbf{r} 3$ rotation; a small portion of labeled $\mathbf{r} \mathbf{4}^{*}$ was left in its original orientation while the rest was rotated. Subsequently, the otic ectoderm was partially ablated. In this embryo, a large stream of labeled cells moved toward the second branchial arch (II), moving past an ectopic otic vesicle (asterisk) that formed adjacent to the $\mathrm{r} 2 / 4$ border. (C) A whole-mount epifluorescence view of the same embryo illustrates that in addition to the large caudally directed stream (large arrow), there is a small stream of labeled cells (smaller arrow) that emerged from the unrotated labeled $\mathbf{r} \mathbf{4}^{*}$. Interestingly, both the large and small streams converged on the same region above the second branchial arch (II), in the region of the first epibranchial placode. (D) Phase plus epifluorescence image of a longitudinal section through the embryo pictured in A-C showing some labeled cells (arrows) adjacent to both the endogenous (OT) and ectopic (eOT) otic vesicles. (E) An embryo in which r4 was labeled with DiI and the otic vesicle was partially ablated, resulting in its caudal displacement and diminution in size. DiI-labeled neural crest cells migrated caudally toward the rostral portion of the otic vesicle and then into the second (II) and third branchial (III) arches. An open arrow indicates labeled cells in arch II and a closed arrow indicates labeled cells in arch III. The long thin arrow indicates the cleft between the two arches. Normally, r4 neural crest cells only enter the second arch. Bar, $240 \mu \mathrm{m}$ in A; $100 \mu \mathrm{m}$ in B; $70 \mu \mathrm{m}$ in C; $35 \mu \mathrm{m}$ in D; and $50 \mu \mathrm{m}$ in E. 

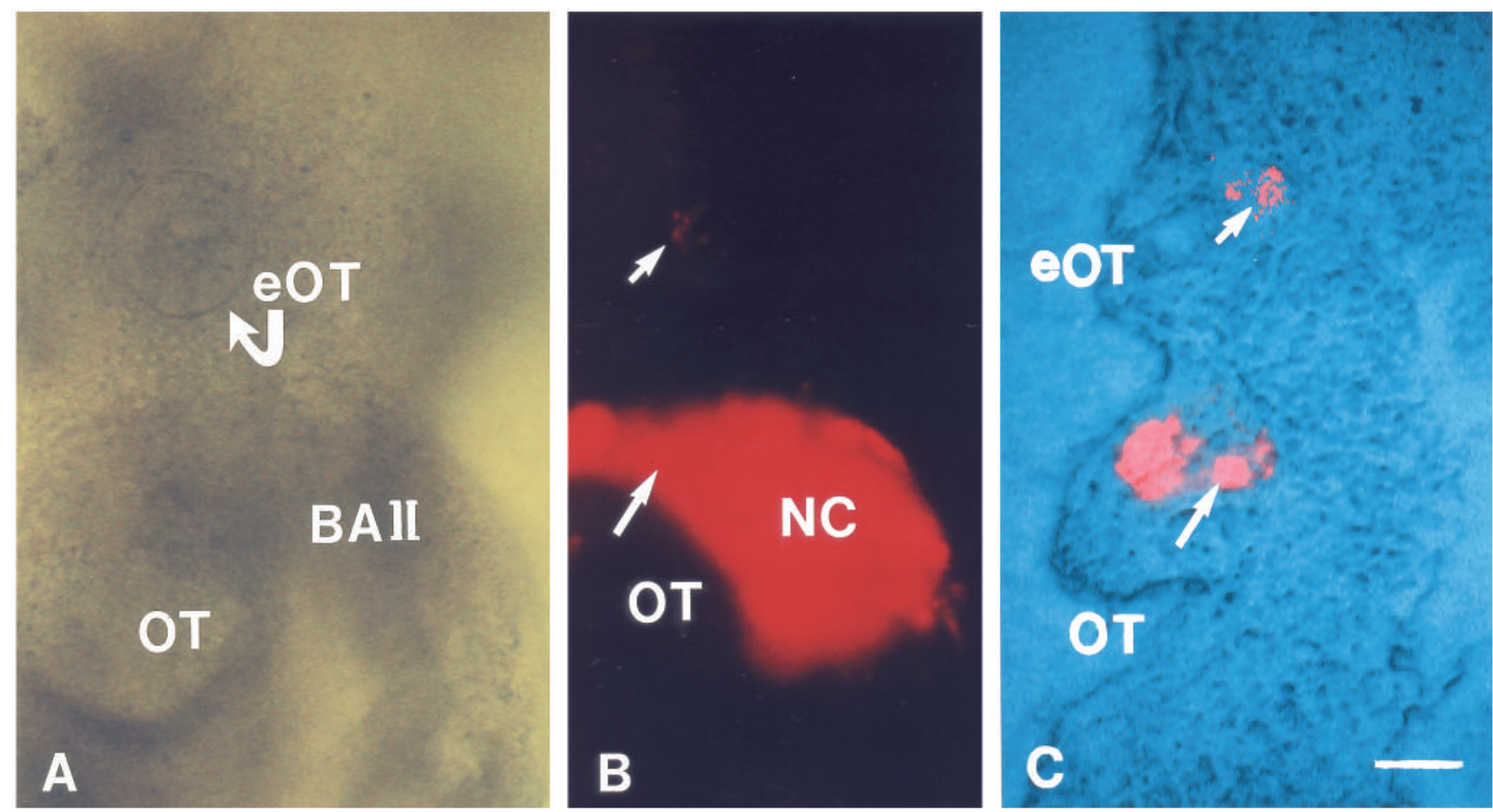

Fig. 10. Grafting of an additional otic vesicle. (A) Whole-mount phase contrast image of a 20-ss embryo in which DiI label was injected into r4 and an otic placode was grafted at the $\mathrm{r} 2 / 3$ border at the 10 -ss. The ectopic otic vesicle (eOT) formed rostral to the endogenous otic vesicle (OT). (B) Rhodamine epifluorescence whole-mount image of the same embryo demonstrates a prominent stream (large arrow) of DiI-labeled r4 cells migrating laterally toward the second branchial arch. In addition, a small group consisting of 4-5 labeled cells (small arrow) was observed at the rostral margin of the grafted otic vesicle. (C) Epifluorescence image of a sagittal section through the embryo shown in (A,B). DiI-labeled cells are evident adjacent to the rostral portion of both the endogenous (OT; large arrow) and grafted (eOT; short arrow) otic vesicle. BAII = second branchial arch; $\mathrm{NC}$, neural crest. Bar, $70 \mu \mathrm{m}$ in $\mathrm{A}, \mathrm{B} ; 40 \mu \mathrm{m}$ in $\mathrm{C}$.

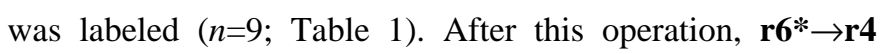
migrated ventrolaterally toward the second branchial arch, following a similar pattern to that of unoperated $\mathrm{r} 4$ cells $(n=5$ embryos). Similarly, labeled $\mathbf{r} \mathbf{4}^{*} \rightarrow \mathbf{r 6}$ migrated caudally and laterally, below the endogenous otic vesicle in 4/4 embryos, as would cells from unoperated r6. However, in 2 embryos, some of the transposed $\mathbf{r} 4 *$ cells migrated caudally around the otic vesicle and then turned rostrally toward the rostral portion of the endogenous otic vesicle (Fig. 6A,B) and first epibranchial placode (data not shown), where $\mathrm{r} 4$ neural crest cells normally migrate.

\section{Rostrocaudal rotation of ectoderm/mesoderm adjacent to $\mathbf{r}$ and $\mathbf{r} 4$}

To test whether the ectoderm/mesoderm plays a role in patterning the hindbrain neural crest cells, the neural tube at $\mathrm{r} 3$ or r4 was labeled by a focal injection of DiI, followed by unilateral rotation of the adjacent ectoderm and underlying mesoderm $(\mathbf{m 3} \rightarrow \mathbf{m} 4$; Figs 7, 8). In 9/14 embryos, this operation resulted in no difference in the pattern of neural crest migration between the operated and unoperated side. When r3* was labeled followed by $\mathbf{m} 3 \rightarrow \mathbf{m} \mathbf{4}$ translocation, labeled neural crest cells deviated rostrally toward the first branchial arch or caudally toward the endogenous otic vesicle (Fig. 7A), whereas those emerging from $\mathrm{r} 4$ after $\mathbf{m} 3 \rightarrow \mathbf{m} \mathbf{4}$ migrated laterally toward the rostral portion of the otic vesicle and second branchial arch (Fig. 8B). These patterns are identical to those observed in unoperated embryos (Fig. 8A), even though the $\mathbf{m} 3 \rightarrow \mathbf{m} 4$ rotation results in an altered peripheral environment, as evidenced by caudal displacement of the branchial cleft from the r2/3 to the r3/4 border (Fig. 8B).

To ascertain that both the mesoderm and ectoderm had been rotated, DiO was injected into the mesoderm adjacent to $\mathrm{r} 3$ (Fig. 7B), which was subsequently rotated lateral to $\mathbf{r} 4 *$ (Fig. 7C). The DiI-labeled neural crest cells from $\mathrm{r} 4$ intermingled with the DiO-labeled mesoderm from m3 (Fig. 7D,E), consistent with our previous data from $\mathbf{r} 4 * \rightarrow \mathbf{r} 3$ rotations showing that neural crest cells are able to migrate through this mesenchyme.

In the remaining 5/14 embryos, a small ectopic otic vesicle was formed at the rostral border of the $\mathbf{m 3} \rightarrow \mathbf{m} \mathbf{4}$ graft. These embryos had a larger stream of cells that migrated toward the endogenous otic vesicle and second arch as well as a smaller cluster that migrated toward the accessory otic vesicle (Fig. $8 \mathrm{C}-\mathrm{H})$.

\section{Partial ablation of the otic vesicle}

The above results suggest that some neural crest cells move directionally toward the otic vesicle. In addition, the otic vesicle has been proposed to represent a mechanical barrier to neural crest cells migrating from r5 (Anderson and Meier, 1981), which appear to deviate rostrally and caudally around it. To examine further the role of the otic vesicle, we performed surgical ablations of the ectoderm adjacent to $r 4$ through r6. Despite extensive ablations, we were unable to remove the 
entire otic vesicle, suggesting a surprising regulative capacity of the remaining ectoderm. As a consequence, the operated embryos $(n=7)$ had partial otic vesicle ablation, with the vesicle being reduced in size and displaced caudally. In 3/7 embryos in which $\mathrm{r} 4$ was labeled with DiI prior to ablation, labeled cells deviated caudally toward the displaced otic vesicle and subsequently migrated into both the second and third branchial arches (Fig. 9E). This contrasts with the movement of $\mathrm{r} 4$ cells in unoperated embryos, which move laterally into the second branchial arch only.

Partial ablation of the otic vesicle also altered the pattern of neural crest migration after neural tube transposition. After $\mathbf{r} \mathbf{4}^{*} \rightarrow \mathbf{r} 3$ rotation together with partial otic vesicle ablation $(n=6)$, DiI-labeled cells moved further caudad toward the displaced otic vesicle and epibranchial placode than in unoperated embryos (Fig. 9A,B compared with Fig. 2B). In addition, labeled cells moved toward and beyond the ectopic otic vesicle that formed at the r2/4 graft border (Fig. 9C). In the embryo illustrated in Fig. 9A-B, DiI label was injected into $\mathrm{r} 4$ prior to $\mathbf{r} \mathbf{4}^{*} \rightarrow \mathbf{r} 3$ rotation, but a small portion of labeled $\mathbf{r} \mathbf{4}^{*}$ was left in its original orientation while the rest was rotated, followed by partial ablation of the otic ectoderm. A small stream of labeled cells emerged from both the unrotated as well as the rotated portion of labeled $\mathbf{r} \mathbf{4}^{*}$. Interestingly, both streams converged on the same region of the second branchial arch, corresponding to the first epibranchial placode (Fig. 9B). In two embryos in which small ectopic otic vesicles formed at the $\mathrm{r} 2 / \mathrm{r} 4$ graft border and part of the endogenous otic vesicle was surgically ablated, DiI-labeled cells from $\mathbf{r} \mathbf{4}^{*} \rightarrow \mathbf{r} 3$ only migrated rostrally to the extra otic vesicles, not caudally (data not shown).

\section{Grafting of an additional otic vesicle}

To further test the ability of the otic vesicle to attract neural crest cells, an otic placode from 8- to 11-ss embryos was grafted adjacent to the neural tube at the $\mathrm{r} 2 / 3$ border $(n=22$ embryos). In 13/22 embryos examined 18 hours after the operation, a discrete otic vesicle formed (Fig. 10A). When r4 was labeled with DiI, labeled cells moved toward the grafted otic vesicle ( $n=8 / 13$; Fig. 10B,C), in addition to migrating into the second branchial arch. In another 5 embryos, the labeled cells did not deviate rostrally toward the ectopic otic vesicle, only migrating laterally toward the second branchial arch as they do in unoperated embryos.

\section{DISCUSSION}

We have combined microsurgical approaches with dye labeling of specific rhombomeres to examine the mechanisms underlying neural crest cell migration in the hindbrain. Specifically, we examined if: (1) the rhombomeres contain some intrinsic information causing neural crest cells to leave the neural tube surface in a polarized fashion; (2) neural crest cells home toward their targets either by pathway- or target-derived cues; and (3) inhibitory signals, proposed to be in the mesenchyme adjacent to $\mathrm{r} 3$ and the otic vesicle adjacent to r5, govern the pattern of hindbrain neural crest migration.

Our results suggest that neural crest cells from rhombomere 3 exit the surface of the neural tube in a segmental manner. In unoperated embryos, neural crest from r 3 migrate rostrally and caudally to join the r2 and r4 streams (Sechrist et al., 1993), with most exiting the neural tube near the rhombomere borders. In contrast, neural crest cells from $\mathrm{r} 4$ migrate laterally into the second branchial arch and emerge uniformly from the rhombomere (Lumsden et al., 1991). After neural tube transposition, labeled cells from $\mathbf{r} 3 * \rightarrow \mathbf{r} \mathbf{4}$ migrate similarly to cells normally emerging from $\mathrm{r} 4$, moving to and past the otic vesicle into the second branchial arch. However, they appear to leave the neural tube primarily near the $\mathrm{r} 3 / 4$ border. A possible explanation for this polarized exit is that both endogenous and rotated $r 3$ neural crest may tend to preferentially leave the neural tube at distinct sites near the rhombomere borders. This pattern may result from portions of the $r 3$ neural tube being non-permissive for neural crest migration and/or from neural crest cells being selectively attracted to certain exit sites along the neural tube surface. The present results cannot distinguish between these possibilities. However, there is evidence for discrete exit points for axons emanating from the neural tube (Chang et al., 1992), perhaps mediated by chemoattraction.

Previous studies have shown that $\mathrm{r} 3$ through r6 produce abundant neural crest cells (Sechrist et al., 1993); the present results demonstrate that neural crest cells emerge from these rhombomeres even after transposition to ectopic locations. Our findings suggest that emigration of neural crest cells ceases earlier in both normal and rotated $\mathrm{r} 3$ than in other rhombomeres, consistent with the possibility that apoptosis eliminates neural crest cells in $\mathrm{r} 3$ earlier than in other rhombomeres (Graham et al., 1993). However, we find that $r 3$ is able to produce significant numbers of neural crest cells prior to the 12 somite stage.

Labeled cells from $\mathbf{r} \mathbf{4}^{*} \rightarrow \mathbf{r} 3$ emerge from the neural tube, migrate a short distance into the adjacent mesenchyme and then primarily course caudally toward the endogenous otic vesicle and the second branchial arch. In addition, some cells migrate rostrally into the first branchial arch. This is a location which is not normally populated by $\mathrm{r} 4$ cells, suggesting that hindbrain neural crest cells are not completely specified to their targets. One difference between cells emerging from $r 3$ in unoperated embryos and those from $\mathbf{r} \mathbf{4}^{*} \rightarrow \mathbf{r} 3$ is that the mesenchyme adjacent to $\mathrm{r} 3$ is normally free of neural crest cells whereas rotated $\mathbf{r} \mathbf{4}^{*} \rightarrow \mathbf{r} 3$ cells are observed within this mesenchyme. Similarly, $\mathrm{r} 4$ cells migrate through the mesenchyme normally adjacent to $\mathrm{r} 3$, and vice versa, after rotation of the mesoderm. Although this mesenchyme has been proposed to be inhibitory (Sechrist et al., 1993), double-labelling of neural crest cells with DiI and the mesoderm adjacent to $\mathrm{r} 3$ with $\mathrm{DiO}$ suggests that extensive intermingling occurs between the two populations, despite the fact that this mesoderm normally is devoid of neural crest cells. Two possible mechanisms could account for the intermingling of neural crest cells with the mesenchyme adjacent to r3. First, this mesenchyme may not be inhibitory for all neural crest populations. Alternatively, grafted $\mathrm{r} 4$ may respecify properties of the adjacent mesenchyme, rendering it an appropriate migratory substrate. Further experiments are needed to discriminate between these alternatives.

In contrast to the hindbrain region, there is clear evidence in the trunk that the mesodermal somites control the segmental pattern of neural crest migration. Neural crest cells migrate preferentially through the rostral half of each somitic sclerotome, while avoiding the caudal half (Rickmann et al., 1985). 
Rostrocaudal inversion of the somites results in a reversal of the pattern of trunk neural crest migration, such that neural crest cells traverse the originally rostral halves of the somites, even after rotation to a caudal position (Bronner-Fraser and Stern, 1991). Although the molecular differences within the mesoderm are not yet clear, there may be inhibitory cues in the caudal sclerotome, attractive cues in the rostral sclerotome or both. Possible candidates for inhibitors within the caudal portion of the somites include T-cadherin (Ranscht and Bronner-Fraser, 1991), chondroitin sulfate proteoglycans (Oakley and Tosney, 1991) and molecules recognized by peanut lectins (Davies et al., 1990). Other molecules are distributed selectively in the rostral portion of the somite, including butrylcholinesterase (Layer et al., 1988) and tenascin, though the latter appears as a consequence rather than a cause of neural crest migration (Stern et al., 1989).

That tissues other than the rhombomeres can influence hindbrain neural crest cells is demonstrated by the observation that neural crest cells migrate directionally toward an otic vesicle. After transposition of $\mathrm{r} 3$ and $\mathrm{r} 4$, labeled neural crest cells were observed around small ectopic otic vesicles that formed as a consequence of grafting. They also homed toward caudally displaced otic vesicles and intentionally grafted vesicles placed at the $2 / 3$ border. One possible explanation for these results is that the otic vesicle may selectively guide neural crest cells by emitting a chemoattractant. Alternatively, the vesicle and/or the hindbrain primordium may respecify neural crest migratory pathways adjacent to them after grafting. Regardless of the underlying mechanism, the results clearly demonstrate that some neural crest cells home to their targets either by reading specific pathway cues or by selective attraction by the target tissue. Labeled neural crest cells consistently were observed adjacent to the rostral (early neurogenic) region of the otic vesicle as well as the neurogenic region of the epibranchial placodes, raising the intriguing possibility that there may be specific domains within the placodes toward which neural crest cells migrate. The neurogenic region of the otic placode contributes to the same vestibular and acoustic ganglia (cranial nerve VIII) populated by these neural crest cells, whereas the epibranchial placodes generate neurons for the geniculate, petrosal and nodosal ganglia of cranial nerves VII, IX and X (D'Amico-Martel and Noden, 1983). Neural crest cells did not home to the ectopic otic vesicles in all embryos. In the cases where negative results were obtained, it is possible that the vesicle was too far away from the neural crest cells. Alternatively, if there are specific regions (e.g. the rostral neurogenic portion) of the vesicle that are attractive, they may have been excluded in these grafts.

There are a few examples of tissues known to emit chemoattractive cues in the developing nervous system. For example, the floor plate appears to attract commissural axons, which project ventrally toward the neural tube midline and then turn after crossing the floor plate (Tessier-Lavigne et al., 1988). In addition, the maxillary process selectively attracts axons from the trigeminal ganglion (Lumsden and Davies, 1983) and the basilar pons attracts cortical axon collaterals (Heffner et al., 1990). For hindbrain neural crest cells, there may be sequential chemoattractants, since many neural crest cells migrate beyond the otic vesicle toward the epibranchial ectodermal placodes and further ventrally into the branchial arches. Consistent with the idea that other placodes may emit chemoat- tractants, neural crest cells in the Pax- 6 mutant rat, which lacks the nasal placode, fail to migrate into the frontonasal process (Toshihiko et al., 1993).

In addition to its attractive properties suggested here, the otic vesicle has been proposed to act as a mechanical barrier for migrating neural crest cells (Anderson and Meier, 1981). For example, neural crest cells emerging from $\mathrm{r} 5$ deviate around it rostrally and caudally (Sechrist et al., 1993). Because it is an epithelial structure juxtaposed to $\mathrm{r} 5$ and $\mathrm{r} 6$, it is not surprising that some neural crest cells may be trapped between the vesicle and the neural tube. Consistent with the otic vesicle acting as a mechanical barrier, we observed that caudal or ventral displacement of the otic vesicle by partial ablation of the ectoderm results in an altered pattern of neural crest migration. Labeled r4 cells migrate caudally into both the second and third branchial arches, as opposed to those from $\mathrm{r} 4$ in unoperated embryos that only enter the second arch. In addition, r5 cells migrate dorsally over a deeply invaginated otic vesicle, rather than being trapped between the neural tube and otic vesicle. Thus, it is possible that the intact otic vesicle blocks this population of neural crest cells from entering more caudal branchial arches. Furthermore, ablation of the otic placode may result in changes and/or displacement of the adjacent paraxial mesenchyme, perhaps resulting in a better migratory substrate for neural crest cells.

Although the present results support the idea that some influences external to the neural tube affect the pattern of neural crest migration, there is ample evidence that the rhombomeres play a major role in the pattern of neural crest migration. For example, Noden (1983) found that grafting first arch neural crest into the second arch resulted in a duplication of first arch structures, suggesting that premigratory neural crest cells already have some positional information. The homeobox gene code in the hindbrain may be responsible for intrinsic positional information. The vertebrate Hox genes are organized in four paralogous clusters, with the $3^{\prime}-5^{\prime}$ sequence along the chromosome generally corresponding to the order of expression in rhombomeres. Some genes are confined to specific rhombomeres; for example, r3 and r5 selectively express Krox-20 (Wilkinson et al., 1989) and r4 expresses HoxB1 (Hunt et al., 1991). Transplanted rhombomeres maintain expression of inherent homeobox genes even after being grafted to an ectopic site (Guthrie et al., 1992; Kuratani and Eichele, 1993). In addition to expression in rhombomeres, some neural crest cell populations that emerge from the rhombomeres continue to express Hox genes (Hunt et al., 1991). It has been suggested that coordinate expression of Hox genes in rhombomeres and neural crest may specify segment identity in both cell types (Hunt et al., 1991; Kuratani and Eichele, 1993). In support of this idea, inactivation of the HoxAl and HoxA3 genes causes defects in both the hindbrain and branchial neural crest (Chisaka and Capecchi, 1991; Lufkin et al., 1991; Chisaka et al., 1992; Carpenter et al., 1993). Our finding that neural crest from both normal and rotated $\mathrm{r} 3$ exit the neural tube in a polarized manner supports the idea that the rhombomeres contain inherent information. Upon emerging from the neural tube, neural crest cells may be influenced either by pathway- or target-derived cues from tissues such as the otic vesicle. The finding that neural crest cells home toward ectodermally derived placodes is consistent with the idea that the pattern of the "ectomeres" covering the branchial arches may 
be intimately related to that of neural crest cells (Couly and LeDouarin, 1990).

The above results demonstrate that neural crest cells from a number of different rhombomeres can contribute to multiple branchial arches after manipulation of the tissue environment. For example, rotation of the neural tube results in some $\mathrm{r} 4$ cells, which normally contribute only to the second branchial arch, populating both first and third branchial arches as well. Similarly, displacement of the otic vesicle results in $\mathrm{r} 4$ cells migrating toward the second and third branchial arches. The labeled neural crest cells invade these arches despite the fact that their rhombomeres of origin contain the "inappropriate" Hox code. In unoperated embryos as well, multiple rhombomeres contribute neural crest cells to a single branchial arch (Sechrist et al., 1993). Thus, Hox gene expression is unlikely to be the sole determinant of neural crest cell localization. Rather, there may be an interplay between positional information carried by Hox genes and pathway/target-derived influences in controlling the pattern of neural crest cell migration and localization in the hindbrain.

We thank Dr Scott Fraser and Mary Dickinson for invaluable comments on the manuscript and Helene Lesterlin, Simone Lutolf, Roham Zamanian and Parisa Zarbafian for excellent technical assistance with photography, cryosectioning and some embryonic microsurgeries. We also thank Dr Mark Selleck for assistance with some of the computer images. Figures 7B,C were made using an Edge microscope (courtesy of Linda Wegner and Gary Greenberg of Edge Scientific Instrument Corp.) This work was supported by USPHSHD-25138 and a Muscular Dystrophy Grant to M. B.-F.

\section{REFERENCES}

Anderson, C. and Meier, S. (1981). The influence of the metameric pattern in the mesoderm on migration of cranial neural crest cells in the chick embryo. Dev. Biol. 85, 385-402.

Bronner-Fraser, M. and Stern, C. D. (1991). Effects of mesodermal tissues on avian neural crest cell migration. Dev. Biol. 143, 213-217.

Carpenter, E. M., Goddard, J. M., Chisaka, O., Manley, N. R. and Capecchi, M. R. (1993). Loss of Hox-A1 (Hox-1.6) function results in the reorganisation of the murine hindbrain. Development 118, 1063-1075.

Chang, S., Fan, J., and Nayak, J. (1992). Pathfinding by cranial nerve VII (facial) motorneurons in the chick hindbrain. Development 114, 815-823.

Chisaka, O. and Capecchi, M. (1991). Regionally restricted developmental defects resulting from targetted disruption of the mouse homeobox gene Hox-1.5. Nature 350, 473-479.

Chisaka, O., Musci, T. and Capecchi, M. (1992). Developmental defects of the ear, cranial nerves and hindbrain resulting from targeted disruption of the mouse homeobox gene Hox-1.6. Nature 355, 516-520.

Couly, G. and LeDouarin, N. (1990). Head morphogenesis in embryonic chimeras: evidence for a segmental pattern in the ectoderm corresponding to the neuromeres. Development 108, 543-558.

Davies, J., Cook, M., Stern, C. D. and Keynes, R. J. (1990). Isolation from chick somites of a glycoprotein that causes collapse of dorsal root ganglion growth cones. Neuron 4, 11-20.

D'Amico-Martel, A. and Noden, D. M. (1983). Contributions of placodal and neural crest cells to avian cranial peripheral ganglia. Am. J. Anat. 166, $445-468$.

Fraser, S., Keynes, R. and Lumsden, A. (1990). Segmentation in the chick embryo hindbrain is defined by cell lineage restrictions. Nature 334, 431435.

Graham, A., Heyman, I. and Lumsden, A. (1993). Even-numbered rhombomeres control the apoptotic elimination of neural crest cells from odd-numbered rhombomeres in the chick hindbrain. Development 119, 233245.

Guthrie, S. and Lumsden A. (1991). Formation and regeneration of rhombomere boundaries in the developing chick hindbrain. Development 112, 221-9.
Guthrie, S., Muchamore, I., Kuroiwa, A., Marshall, H., Krumlauf, R., and Lumsden, A. (1992). Neuroectodermal autonomy of Hox-2.9 expression revealed by rhombomere transpositions. Nature 356, 157-159.

Hamburger, V. and Hamilton, H. L. (1951). A series of normal stages in the development of the chick embryo. J. Morphol. 88, 49-92.

Harrison, R. G. (1936). Relations of symmetry in the developing ear of Amblystoma punctatum. Proc. Nat. Acad. Sci. USA 22, 238-247.

Heffner, C. D., Lumsden, A. G. S. and O'Leary, D. D. (1990). Target control of collateral extension and directional axon growth in the mammalian brain. Science 247, 217-220.

Hunt, P., Gulisano, M., Cook, M., Sham, M.-J., Faiella, A., Wilkinson, D., Boncinelli, E., and Krumlauf, R. (1991). A distinct Hox code for the branchial region of the vertebrate head. Nature 353, 861-864.

Jeffs, P., Jaques, K. and Osmond, M. (1992). Cell death in cranial neural crest development. Anat. Embryol. 185, 583-588.

Kuratani, S. C. and Eichele, G. (1993). Rhombomere transplantation repatterns the segmental organization of cranial nerves and reveals cellautonomous expression of a homeodomain protein. Development 117, 105117.

Keynes, R. J. and Stern, C. D. (1984). Segmentation in the vertebrate nervous system. Nature (London) 310, 786-789.

Layer, P. G., Alber, R. and Rathjen, F. G. (1988). Sequential activation of butrylcholinesterase in rostral half somites and acetylcholinesterase in motoneurones and myotomes preceding growth of motor axons. Development 102, 387-396.

Lee, V., Carden, M., Schlaepfer, W. and Trojanowski, J. (1987). Monoclonal antibodies distinguish several differentially phosphorylated states of the two largest rat neurofilament subunits (NF-H and NF-M) and demonstrates their existence in the normal nervous system of adult rats. $J$. Neurosci. 7, 3474-3489.

Lufkin, T., Dierich, A., LeMeur, M., Mark, M. and Chambon, P. (1991). Disruption of the Hox-1.6 homeobox gene results in defects in a region corresponding to its rostral domain of expression. Cell 66, 1105-1119.

Lumsden, A. G. S. and Davies, A. M. (1983). Earliest sensory nerve fibres are guided to peripheral targets by attractants other than nerve growth factor. Nature 306, 786-788.

Lumsden, A. G. S. and Keynes, R. J. (1989). Segmental patterns of neuronal development in the chick hindbrain. Nature 337, 424-428.

Lumsden, A., Sprawson, N. and Graham, A. (1991). Segmental origin and migration of neural crest cells in the hindbrain region of the chick embryo. Development 113, 1281-1291.

Noden, D. M. (1975). An analysis of the migratory behavior of avian cephalic neural crest cells. Dev. Biol. 42, 106-130.

Noden, D. M. (1983). The role of the neural crest in patterning of avian cranial skeletal, connective and muscle tissues. Dev. Biol. 96, 144-165.

Oakley, R. A. and Tosney, K. W. (1991). Peanut agglutinin and chondroitin-6sulfate are molecular markers for tissues that act as barriers to axon advance in the avian embryo. Dev. Biol. 147, 187-206.

Ranscht, B. and Bronner-Fraser, M. (1991). T-cadherin expression alternates with migrating neural crest cells in the trunk of the avian embryo. Development 111, 15-22.

Rickmann, M., Fawcett, J. W., Keynes, R. J. (1985). The migration of neural crest cells and growth cones of motor axons through the rostral half of the chick somite. J. Embryo. Exp. Morphol. 90, 437-455.

Sechrist, J., Serbedzija, G., Scherson, T., Fraser, S., and Bronner-Fraser, M. (1993). Segmental migration of the hindbrain neural crest does not arise from segmental generation. Development 118, 691-703.

Stern, C. D., Norris, W. E., Bronner-Fraser, M., Carlson, G. J., Faissner, A., Keynes, R. J., and Schachner, M. (1989). J1/tenascin-related molecules are not responsible for the segmented pattern of neural crest cells or motor axons in chick embryo. Development 107, 309-320.

Tessier-Lavigne, M., Placzek, M., Lumsden, A. G. S., Dodd, J. and Jessell, T. M. (1988). Chemotropic guidance of developing axons in the mammalian central nervous system. Nature 336, 775-778.

Toshihiko, T., Osumi-Yamashita, N., Noji, S., Ohuchi, H., Koyama, E., Nyokai, F., Matsuo, N., Taniguchi, S., Doi, H., Iseki, S., Youichiro, N., Fujiwar, M., Watanae, T. and Eto, K. (1993). A mutation in the Pax-6 gene in rat small eye is associated with impaired migration of midbrain crest cells. Nature Genetics 3, 299-304.

Wilkinson, D. G., Bhatt, S., Chavrier, P., Bravo, R. and Charnay, P. (1989). Segmental expression of Hox-2 homeobox-containing genes in the developing mouse hindbrain. Nature 337, 461-464.

(Accepted 25 March 1994) 